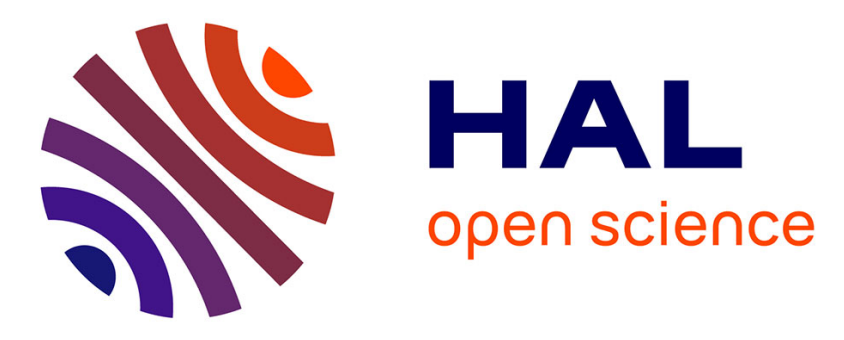

\title{
Temporal and spatial scaling of hydraulic response to recharge in fractured aquifers: Insights from a frequency domain analysis
}

Joachin Jimenez-Martinez, Laurent Longuevergne, Tanguy Le Borgne, Philippe Davy, Anna Russian, Olivier Bour

\section{To cite this version:}

Joachin Jimenez-Martinez, Laurent Longuevergne, Tanguy Le Borgne, Philippe Davy, Anna Russian, et al.. Temporal and spatial scaling of hydraulic response to recharge in fractured aquifers: Insights from a frequency domain analysis. Water Resources Research, 2013, 49 (5), pp.3007-3023. 10.1002/wrcr.20260 . insu-00907357

\section{HAL Id: insu-00907357 https://hal-insu.archives-ouvertes.fr/insu-00907357}

Submitted on 21 May 2014

HAL is a multi-disciplinary open access archive for the deposit and dissemination of scientific research documents, whether they are published or not. The documents may come from teaching and research institutions in France or abroad, or from public or private research centers.
L'archive ouverte pluridisciplinaire HAL, est destinée au dépôt et à la diffusion de documents scientifiques de niveau recherche, publiés ou non, émanant des établissements d'enseignement et de recherche français ou étrangers, des laboratoires publics ou privés. 


\title{
Temporal and spatial scaling of hydraulic response to recharge in fractured aquifers: Insights from a frequency domain analysis
}

\author{
Joaquín Jiménez-Martínez, ${ }^{1}$ Laurent Longuevergne, ${ }^{1}$ Tanguy Le Borgne, ${ }^{1}$ Philippe Davy, ${ }^{1}$ \\ Anna Russian, ${ }^{2}$ and Olivier Bour ${ }^{1}$ \\ Received 31 July 2012; revised 4 February 2013; accepted 14 April 2013; published 31 May 2013.
}

[1] Quantification of the recharge in fractured aquifers is particularly challenging because of the multiscale heterogeneity and the range of temporal scales involved. Here we investigate the hydraulic response to recharge of a fractured aquifer, using a frequency domain approach. Transfer functions are calculated in a range of temporal scales from 1 day up to a few years, for a fractured crystalline-rock aquifer located in Ploemeur (S Brittany, France), using recharge and groundwater level fluctuations as input and output respectively. The spatial variability of the response to recharge (characteristic response time, amplitude, temporal scaling) is analyzed for 10 wells sampling the different compartments of the aquifer. Some of the transfer functions follow the linear reservoir model behavior. On the contrary, others display a temporal scaling at high frequency that cannot be represented by classic models. Large-scale hydraulic parameters, estimated from the low-frequency response, are compared with those estimated from hydraulic tests at different scales. The variability of transmissivity and storage coefficient tends to decrease with scale, and the average estimates converge toward the highest values at large scale. The small-scale variability of diffusivities, which implies the existence of a range of characteristic temporal scales associated with different pathways, is suggested to be at the origin of the unconventional temporal scaling of the hydraulic response to recharge at high frequency.

Citation: Jiménez-Martínez J., L. Longuevergne, T. Le Borgne, P. Davy, A. Russian, and O. Bour, (2013), Temporal and spatial scaling of hydraulic response to recharge in fractured aquifers: Insights from a frequency domain analysis, Water Resour. Res., 49, 3007-3023, doi:10.1002/wrcr.20260.

\section{Introduction}

[2] Characterization and quantification of the recharge processes in fractured aquifers, which sustain human water consumption and irrigation in a large part of the world, are key issues for managing these resources [Gustafson and Krásný, 1994; National Research Council, 1996; Long et al., 1996; Neuman, 2005]. This task is particularly challenging, since fracture networks are characterized by multiscale heterogeneity, which implies a strong spatial variability of the hydraulic properties and potential dependency of the hydraulic behavior (see Figure 1) [Bour and Davy, 1997; Tsang and Neretnieks, 1998; Bonnet et al., 2001; Bour et al., 2002; Neuman and Di Frederico, 2003; de Dreuzy et al., 2002, 2004; Bockgard and Niemi, 2004; Gleeson et al., 2009].

[3] On a regional scale, the recharge of fractured aquifers may be highly dependent on the dip of the main perme-

\footnotetext{
${ }^{1}$ Geosciences Rennes UMR 6118 CNRS, Université de Rennes I, Rennes, France.

${ }^{2}$ Institute of Environmental Assessment and Water Research (IDAEA), CSIC, Barcelona, Spain.

Corresponding author: J. Jiménez-Martínez, Geosciences Rennes UMR 6118 CNRS, Université de Rennes I, Campus de Beaulieu, Rennes 35042, France. (joaquin.jimenez-martinez@univ-rennes1.fr)

C2013. American Geophysical Union. All Rights Reserved. 0043-1397/13/10.1002/wrcr.20260
}

able structures, fracture properties (length, aperture, filling) and fracture organization, which determine the extent of the hydrogeological catchment [e.g., Bockgard and Niemi, 2004; Gleeson et al., 2009; Ruelleu et al., 2010]. Furthermore, the existence of preferential flow paths typically leads to rapid recharge [Molenat et al., 1999; Gleeson et al., 2009; Trinchero et al., 2011]. The main connected clusters of fractures can be characterized by different field investigation methods, including flowmeter tests [Paillet, 1998; Williams and Paillet, 2002; Le Borgne et al., 2006a, 2007], hydraulic tests [Day-Lewis et al., 2000; Illman et al., 2009], ground penetrating radar imaging [Day-Lewis et al., 2003; Talley et al., 2005; Tesoflias and Hoch, 2006] and tracer tests [Becker and Shapiro, 2003]; see also the review of Hubbard and Linde [2011] on hydrogeophysical methods.

[4] Although detailed investigations of fractured media heterogeneity are necessary, they cannot be directly used for long-term predictions. For instance, long-term recharge may be controlled not only by the rapid preferential flow paths but also by the entire fracture network, including less permeable fractures, which can play an important role in water storage in the long term. The scale dependency of transmissivity in heterogeneous media has been thoroughly investigated in field and numerical studies [e.g., SanchezVila et al., 1996; de Dreuzy et al., 2002; Neuman and Di Frederico, 2003; Molz et al., 1990; Clauser, 1992; Guyonnet et al., 1993; Rovey and Cherkauer, 1995; Hsieh, 1998; 


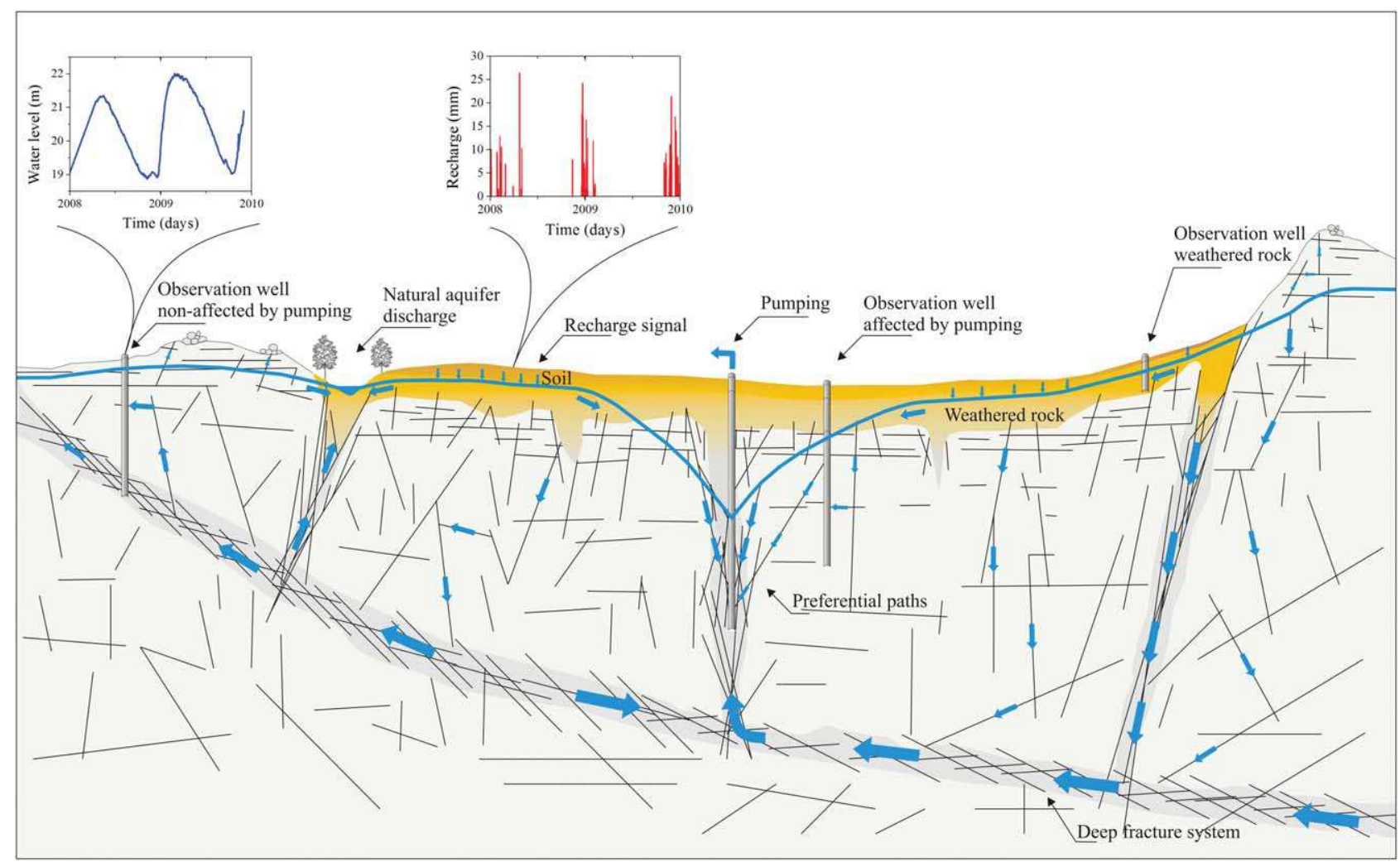

Figure 1. Conceptual scheme of a fractured aquifer. Fracture networks are characterized by a multiscale heterogeneity. Arrow size represents the relative contribution to the flow of the different structures.

Shapiro, 2003; Maréchal et al., 2004; Martinez-Landa and Carrera, 2005; Illman, 2006; Dewandel et al., 2012]. In contrast, less is known about scaling of the storage coefficient or porosity parameters which are key factors in recharge quantification [e.g., Sanchez-Vila et al., 1999; Vesselinov et al., 2001; Illman, 2005]. Furthermore, these heterogeneity and scale effects have led to questioning of the relevance of equivalent effective models in representing upscaled hydraulic behavior [e.g., Neuman and Di Frederico, 2003; Le Borgne et al., 2004].

[5] Frequency domain approaches can be used to analyze the large-scale response of hydrologic systems to recharge [e.g., Gelhar, 1974]. Analyses of the spectral amplitude of river or spring discharge have been used to assess large-scale hydraulic behavior and to quantify the characteristic response times and equivalent hydraulic properties of karstic and fractured systems [e.g., Molenat et al., 1999; Long and Derickson, 1999; Manga, 1999; Lee and Lee, 2000; Jukic and Denic-Jukic, 2004]. Fewer studies have investigated the spatial variability of the hydraulic response to recharge, using hydraulic heads [Zhang and Schilling, 2004; Zhang and Li, 2005]. Zhang and Schilling [2004] found that the hydraulic head at several monitoring wells in the same heterogeneous sedimentary aquifer could show a distinct dependency of the spectral amplitude on frequency, with an apparent fractal behavior suggesting an impact of heterogeneity on the well response temporal scaling behaviors.

[6] Here we use a frequency domain analysis to characterize recharge mechanisms in a fractured crystalline-rock aquifer system located at Ploemeur (southern Brittany,
France), over a frequency band from 2 days to 3.5 years. The data set includes hydraulic head data recorded at ten monitoring wells. Our objective is to analyze the spatial variability of the response to recharge, in terms of amplitude, characteristic time and scaling of the spectral amplitude with frequency. These large-scale estimates are then compared with hydraulic properties estimated on the same site to investigate the effects of scale on transmissivity and storage parameters. Section 2 describes the frequency domain analysis. Section 3 presents the study site and the data set. Section 4 discusses the results of the frequency domain analysis and the consequences on temporal and spatial scaling of the hydraulic response to recharge in this fractured aquifer.

\section{Frequency Domain Analysis}

[7] The analysis of hydrologic time series in the frequency domain has been used for a long time to characterize hydrologic systems [Gelhar, 1974]. We recall here the main elements of this approach, which are necessary to follow the analysis. We detail in particular the adaptation of the transfer function analysis for hydraulic heads instead of river discharge.

\subsection{Transfer Function}

[8] Considering a linear and stationary system, its response $y(t)$ to a solicitation $x(t)$ may be expressed as the temporal convolution 


$$
y(t)=(g * x)(t)=\int_{-\infty}^{+\infty} \mathrm{h}(t-\tau) x(\tau) \mathrm{d} \tau,
$$

where $\mathrm{h}(t)$ is the impulse response function. This convolution may be rewritten in the frequency domain by introducing the Fourier transform of the input function $x(t)$

$$
X(\omega)=\int_{-\infty}^{+\infty} x(t) e^{i \omega t} \mathrm{~d} t
$$

where $i^{2}=-1$; and angular frequency $\omega=2 \pi f$, with frequency $f$. The power spectrum is defined as $\phi_{x x}=|X(\omega)|^{2}$. Considering the respective Fourier transform $Y(\omega)$ and $H(\omega)$ of $y(t)$ and $\mathrm{h}(t)$, the frequency domain equivalent of the convolution is the multiplication

$$
Y(\omega)=H(\omega) X(\omega)
$$

where $H(\omega)$ is the frequency response function [Lumley and Panofsky, 1964; Priestley, 1981]. Thus, the transfer function is defined as the square modulus of the frequency response function $|H(\omega)|^{2}$, and provides the gain/attenuation in amplitude that will occur between the input and output at a given frequency.

[9] In practice, the finite length of physical signals leads to spectral leakage on spectrum (i.e., sidelobes on spectrum) and to noisy transfer functions when computed as the simple division of spectrums [Priestley, 1981]. The Wiener-Khinchin theorem states that the power spectrum is

$$
\phi_{x x}(\omega)=\int_{-\infty}^{+\infty} \mathrm{r}_{x x}(\tau) e^{i \omega \tau} \mathrm{d} \tau
$$

where $\mathrm{r}_{x x}$ is the auto-correlation function of signal $x$ (input)

$$
\mathrm{r}_{x x}(t)=E[x(\tau) x(t-\tau)]
$$

and $E[\quad]$ the expected value. Equivalently, the crosspower spectral density between signals $x$ (input) and $y$ (output), $\phi_{x y}$, determined from the cross-correlation functions, allows the frequency response function to be rewritten as

$$
\phi_{x y}(\omega)=H(\omega) \phi_{x x}(\omega)
$$

[10] Computing the frequency response function of the ratio between $\phi_{x y}$ and $\phi_{x x}$ is more robust than the division of the power spectra and yields smoother results in the presence of noise [Priestley, 1981]. Note that the stationary constraint here for the signal analysis is weak, the power spectral density of a signal exists if the signal is in a widesense stationary process (invariance of first and second moments with time).

[11] In general terms, a hydrological system is equivalent to a low-pass filter, filtering high-frequency oscillations and reacting to seasonal or annual climatic ones. The log$\log$ shape of the transfer function versus frequency can be divided into three sections for its analysis (Figure 2), related to physical properties of the aquifer [Gelhar, 1974; Molenat et al., 1999]: (1) The constant asymptotic behavior at low frequency, which is related to the long term fluxstate relationship (e.g., discharge or recession coefficient);

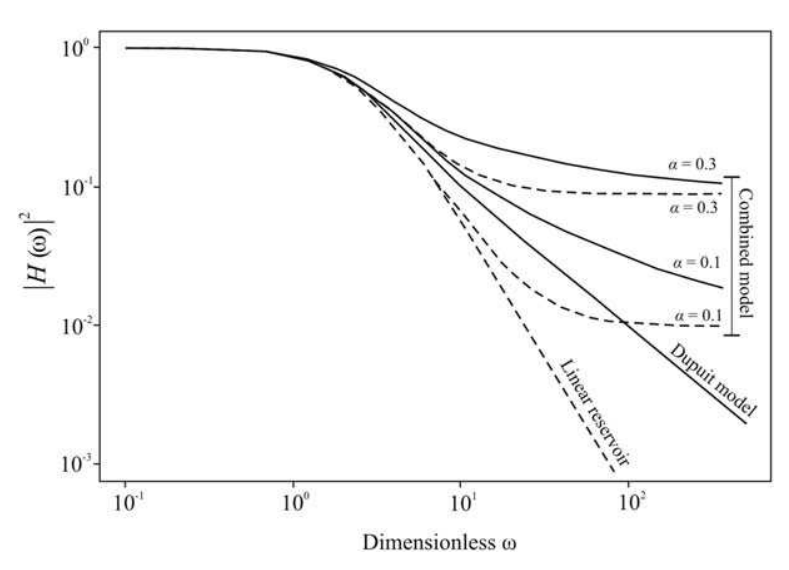

Figure 2. Dimensionless parametric transfer function for Linear reservoir (dashed line), Dupuit model (solid line), and combined model as a function of different $\alpha$ values (modified from Molenat et al. [1999]).

(2) An inflexion point between low and mid frequency, which provides the characteristic response time of the system; and finally (3) The log-log slope between mid and high frequency, which provides information about the recharge mechanisms controlling the aquifer response (e.g., flow line geometry, preferential flows).

[12] There are two main assumptions in this approach: (i) weak stationarity, namely, time invariance of the first and second moments of the hydraulic properties and all boundary conditions, and (ii) linearity [e.g., Gelhar, 1974; Duffy et al., 1984; Molenat et al., 1999; Trinchero et al., 2011]. Notice that the nonlinear assumption [e.g., Jin and Duffy, 1994; Smith, 2008] and nonstationary behaviors [e.g., Li and McLaughlin, 1991, 1995; Zhang and Li, 2005] have been less discussed in the literature. Finally, note that most hydrologic applications employ a parametric transfer function [e.g., Besbes and de Marsily, 1984] in which a shape is assumed (e.g., lognormal), which can be described by a few parameters. However, nonparametric transfer functions are commonly employed in solute transport problems [e.g., Neuman and de Marsily, 1976; Skaggs et al., 1998; Fienen et al., 2006; Cirpka et al., 2007]. Parametric methods tend to be better adapted (i.e., provide less noisy results) to short time series analysis, but require assumptions about the behavior of the system, as described above.

\subsection{Conceptual Models of Flow}

[13] Different analytical models have been proposed to describe the spectral response characteristics of aquifers subject to time variable recharge. A brief summary of the existing flow models for interpreting transfer functions is presented in this section. For an exhaustive explanation the reader is referred to Gelhar [1974] and Molenat et al. [1999].

[14] The Linear reservoir system representation neglects the spatial variation of the water level and considers that the average thickness of the saturated zone can be represented as a function of time $h(t)$. The balance equation can be written as

$$
S \frac{\partial h(t)}{\partial t}=a\left(h(t)-h_{0}\right)-r(t),
$$


where $S$ is the storage coefficient $\left[\mathrm{L}^{3} \mathrm{~L}^{-3}\right] ; a$ the discharge constant or recession coefficient $\left[\mathrm{T}^{-1}\right] ; h$ the aquifer hydraulic head $[\mathrm{L}] ; h_{0}$ the reference level in some adjacent body of water [L]; and $r$ is the aquifer recharge rate [L $\left.\mathrm{T}^{-1}\right]$. The transfer function for the linear model relating the groundwater level and the aquifer recharge is

$$
\left|H_{h}(\omega)\right|_{\text {Lin }}^{2}=\frac{\phi_{h h}}{\phi_{r r}}=\frac{1}{a^{2}+(S \omega)^{2}}
$$

where the characteristic time scale of the system, also referred to as the hydraulic response time by Gelhar [1993], is defined as

$$
t_{L}=\frac{S}{a}
$$

[15] By equivalence with the Dupuit model [Gelhar and Wilson, 1974], which is presented below, the discharge constant parameter for the linear reservoir becomes

$$
a=\frac{3 T}{L^{2}}
$$

where $T$ is the average transmissivity of the aquifer $\left[\mathrm{L}^{2}\right.$ $\mathrm{T}^{-1}$ ]; and $L$ is the aquifer length [L].

[16] The Dupuit model considers the spatial variation of water level. It is based on the Dupuit-Forchheimer hypothesis which assumes that the flow lines in the aquifer are horizontal and the hydraulic gradient is equal to the slope of the water table [Bear, 1979]. The one-dimensional linearized form of the classical Dupuit approximation is given by

$$
S \frac{\partial h(x, t)}{\partial t}=T \frac{\partial^{2} h(x, t)}{\partial x^{2}}+r(t)
$$

where $h(x, t)$ is the thickness of the saturated zone [L]; $x$ the horizontal position [L]; $S$ the storage coefficient $\left[\mathrm{L}^{3} \mathrm{~L}^{-3}\right]$; $T$ the average transmissivity of the aquifer $\left[\mathrm{L}^{2} \mathrm{~T}^{-1}\right]$; and $r$ is the average recharge per unit area $\left[\mathrm{L} \mathrm{T}^{-1}\right]$. The following boundary conditions are applied

$$
\begin{array}{ll}
x=0, & h=0 \\
x=L, & \frac{\partial h}{\partial x}=0
\end{array}
$$

where $L$ is the aquifer length [L].

[17] With the linear reservoir model, the discharge flux and groundwater level fluctuation are proportional (equation (7)) [Gelhar and Wilson, 1974], but this is not the case for the Dupuit model. However, water level fluctuation and stream discharge are proportional if the observation point is located close to the aquifer discharge point. The Darcy flux at the discharge point can be approximated by

$$
q=-\left.\frac{T}{b} \frac{\partial h}{\partial x}\right|_{x=x_{0}} \simeq-\frac{T}{b} \frac{h-h_{0}}{x-x_{0}},
$$

where $h_{0}$ is the boundary condition at $x=x_{0}$ (equation (11)); and $b$ is the aquifer thickness or saturated thickness for confined and unconfined aquifers, respectively [L]. The transfer function for the discharge flux can be expressed as a function of the transfer function for the groundwater level and vice versa

$$
\left|H_{q}(\omega)\right|_{\text {Dup }}^{2}=\frac{\phi_{q q}}{\phi_{r r}}=\left(\frac{T}{b \varepsilon}\right)^{2}\left|H_{h}(\omega)\right|_{\text {Dup }}^{2},
$$

with $\varepsilon=\left(x-x_{0}\right) \ll L$.

$\left|H_{h}(\omega)\right|_{\text {Dup }}^{2}=\left(\frac{b \varepsilon}{T}\right)^{2}\left[\frac{1}{\Omega} \tanh \left((1+i) \sqrt{\frac{1}{2} \Omega}\right) \tanh \left((1-i) \sqrt{\frac{1}{2} \Omega}\right)\right]$.

[18] The dimensionless frequency is defined in this case as $\Omega=\left(t_{D} \omega\right)$, with

$$
t_{D}=\frac{\left(L^{2} S\right)}{T},
$$

[19] $t_{D}^{-1}$ is termed the aquifer response rate [Erskine and Papaioannou, 1997]. The discharge constant or recession coefficient $a\left[\mathrm{~T}^{-1}\right]$ for the Dupuit model proposed becomes

$$
a=\frac{T}{b \varepsilon} .
$$

[20] Note that applying no flux condition at $x=L$ (equation (12)) and under steady-state conditions, the average behavior of a Dupuit aquifer can be approximated by a first order lumped linear system (equation (7)) [Gelhar and Wilson, 1974].

[21] The Combined model [e.g., Molenat et al., 1999; Trinchero et al., 2011] includes two flow components by adding a rapid flow component to one of the flows described above. The transfer function is given by

$$
\left|H_{h}(\omega)\right|_{\text {Comb }}^{2}=\left(H_{h}(\omega)(1-\alpha)+\alpha\right)\left(H_{h}^{*}(\omega)(1-\alpha)+\alpha\right),
$$

where $H_{h}^{*}(\omega)$ is the complex conjugate of $H_{h}(\omega) ; \alpha$ is a coefficient representing the fraction of input that acts as a rapid component (i.e., delta function response in time) of flow through the fractures, and $(1-\alpha)$ the flow through the matrix (e.g., filler fractures, weathered rock).

[22] Finally, vertical flow effects (Laplace model) have been discussed by Gelhar [1974] and Verma and Brutsaert [1971]. This model is equivalent to the Dupuit model for the commonest case of the aquifer length being greater than its thickness.

[23] The transfer function $|H(\omega)|^{2}$ for the linear reservoir and Dupuit models scales at high frequency as $\left|H_{h}(\omega)\right|_{\text {Lin }}^{2} \sim \omega^{-2}$, and $\left|H_{h}(\omega)\right|_{\text {Dup }}^{2} \sim \omega^{-1}$, respectively. For the combined model, the occurrence of rapid flow is reflected in the flattening of the asymptotic behavior at high frequency, $\left|H_{h}(\omega)\right|_{\text {Comb }}^{2} \sim \alpha^{2} \omega^{-0}$, with $\alpha$ a constant (Figure 2), meaning that the system response to the preferential recharge process is the same for a range of frequencies. The spectral expressions for the linear reservoir and Dupuit model can be equivalent at low frequency for an appropriated value of the $a$ coefficient (equation (10)), therefore, the average behavior of a Dupuit aquifer can be 

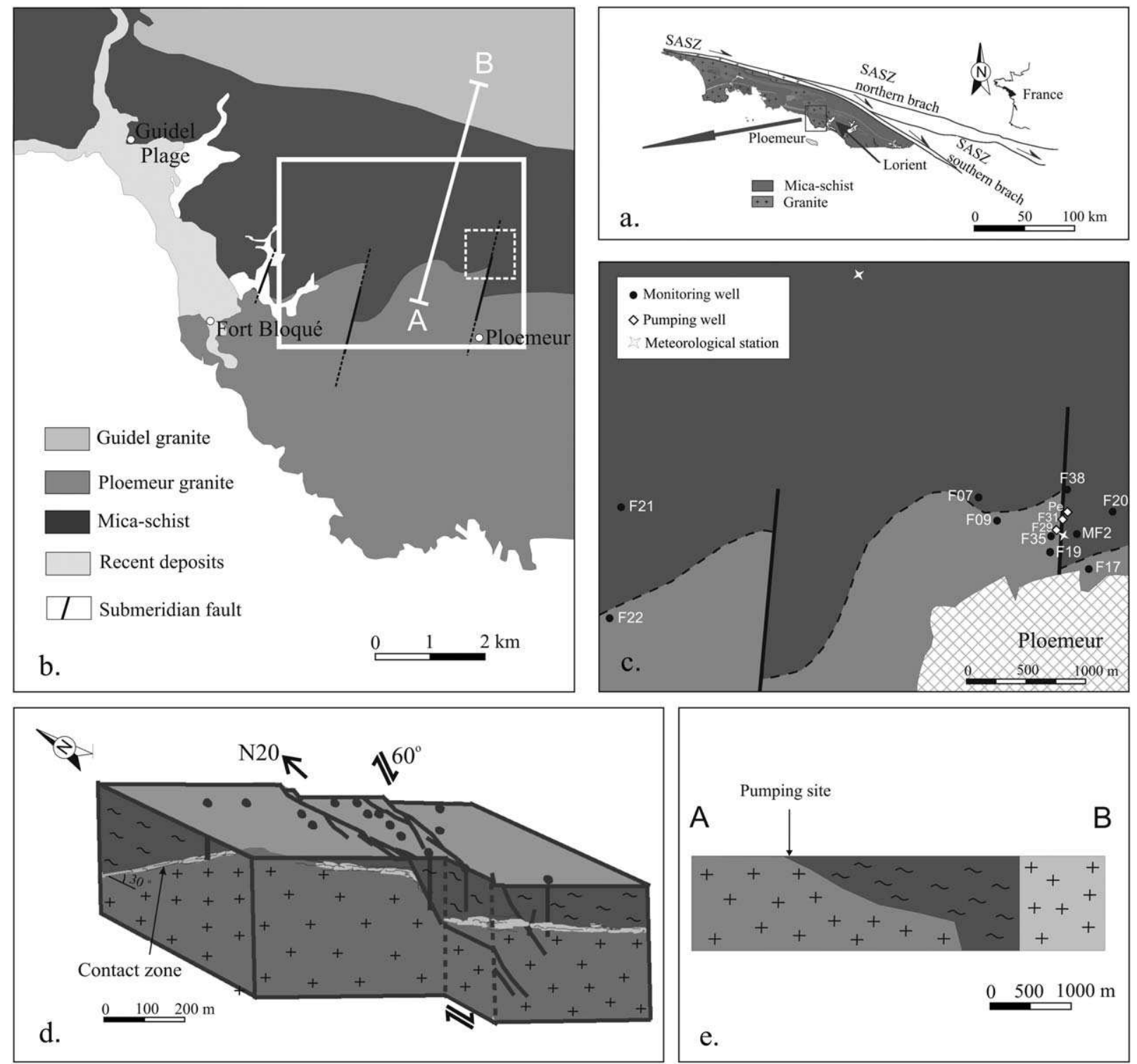

Figure 3. (a) Geological context of the Ploemeur area, South Brittany. SASZ, South Armorican Shear Zone. (b) Synthetic geological map of Ploemeur area. (c) Map location of monitoring and pumping wells, and meteorological stations. (d) 3-D diagram block of the pumping area showing the regional contact dipping toward north and the N20 dextral normal fault (modified from Ruelleu et al. [2010]). (e) Schematic south-north cross section of the site. Pumping site location.

approximated by a linear reservoir [Gelhar and Wilson, 1974] for periods above the characteristic time.

\section{Study Area and Data Set}

\subsection{The Ploemeur Fractured Aquifer}

[24] The Ploemeur crystalline bedrock aquifer is formed by fractured igneous and metamorphic rocks, granite dykes (aplites and pegmatites) and mica-schist (Figure 3). Compared to other aquifers located in similar geological contexts, this confined aquifer is outstandingly productive, with an exploitation rate of $10^{6} \mathrm{~m}^{3}$ per year since 1991 . The structural analysis reported by Touchard [1999] and subsequently by Ruelleu et al. [2010] showed that the pumping site is located at the intersection of two main structures: the contact zone between granite roof and overlaying mica-schist, which dips moderately to the North $\left(\sim 30^{\circ}\right)$, and a subvertical fault zone striking North $\left(20^{\circ}\right)$, which is partly affected by preferential weathering (Figure $3 \mathrm{~d})$. The rocks in most of the area have not undergone significant weathering except in the first few meters, to a depth of $30 \mathrm{~m}$ maximum, around the pumping site. Before the pumping activities were set up, the site was a natural aquifer discharge area with preferential upward fluxes. The initiation of water production led to declining water levels during the first years of operation, but since 1997, the average water levels have stabilized.

[25] The hydrogeology of the area is characterized by strongly heterogeneous permeability, related to the fracture aperture and connectivity [Le Borgne et al., 2004, 2006a, 

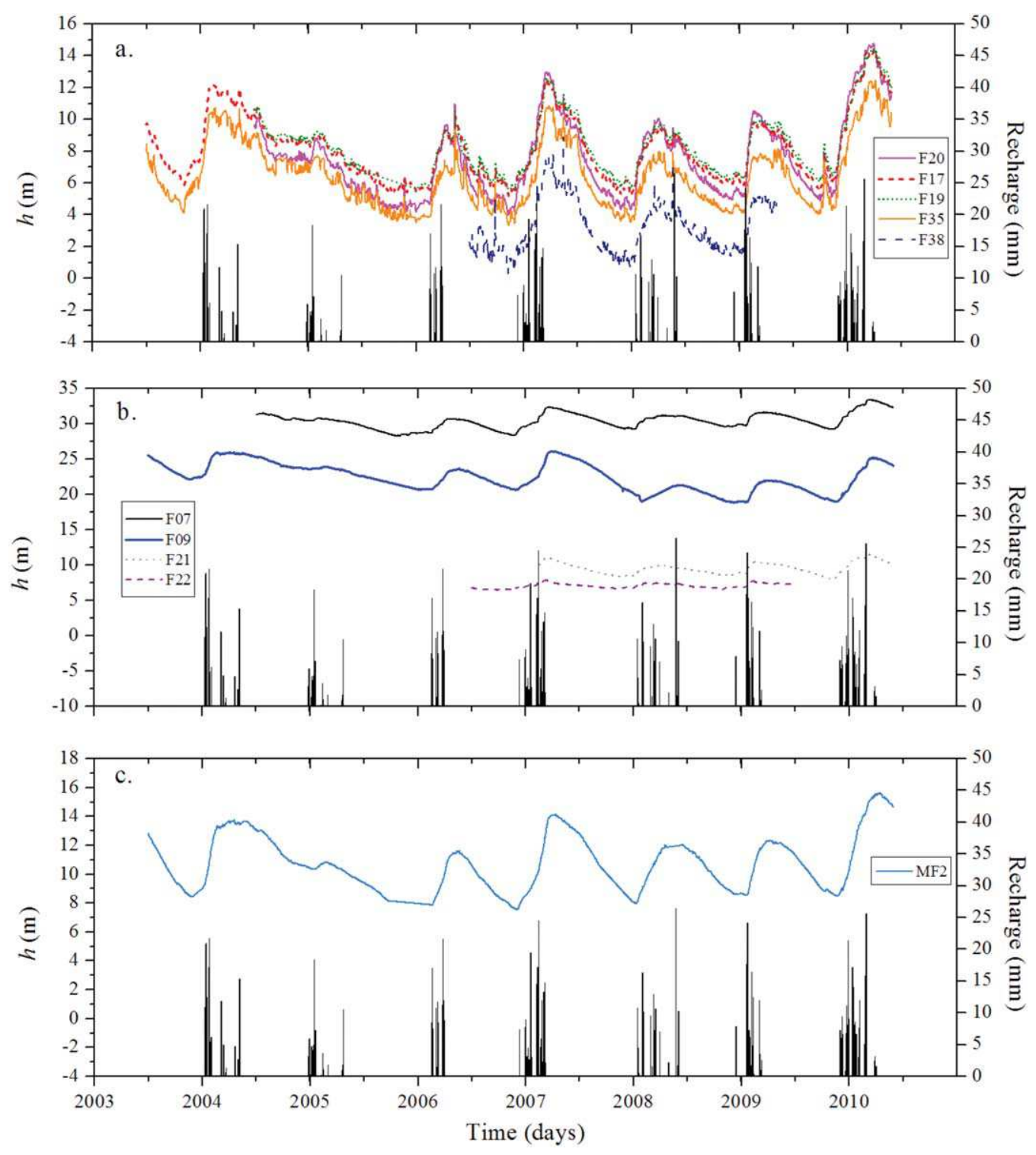

Figure 4. Recharge and groundwater level fluctuations $(h)$ for monitoring wells (a) located around the pumping site, i.e., F20, F17, F19, F35, and F38; (b) located further from the pumping site, i.e., F09, F07, F21, and F22; and (c) representative of the weathered rock, i.e., MF2.

2006b, 2007]. Three main hydrogeological zones can be distinguished (Figure 3d) as follows: the pumping site zone, corresponding to the intersection between the subvertical fault zone (N20) and the contact zone between granite and mica-schist, is the most productive unit where water fluxes are localized; the overlaying mica-schist formation, which includes less permeable fractures, with several grouping orientations; and the weathered rock, which varies in thickness and may have a locally high clay content, hence forming locally aquifer compartments. The site is monitored by several wells, and the deepest ones generally crossing few significant fractures [Le Borgne et al., 2006a]. Most of the wells are screened over their entire depth, except for the first 10-20 m and most of the boreholes are not cemented in their upper part.

[26] The mean annual precipitation is $900 \mathrm{~mm} \mathrm{yr}^{-1}$ (period 2003-2010) and the potential evapotranspiration (by Penman-Monteith) is $750 \mathrm{~mm} \mathrm{yr}^{-1}$. Surface runoff at the experimental site is limited (topographic catchment surface of $\left.5.5 \mathrm{~km}^{2}\right)$, due to the flat topography $(20 \mathrm{~m}$ elevation range over $2.7 \mathrm{~km}$ ) and the type of precipitation, which is evenly distributed throughout the year in events of small intensity.

\subsection{Data Set}

[27] The data set used in this study includes piezometric levels monitored in several wells (five monitoring wells close to the pumping site, (F20, F17, F19, F35, and F38); four monitoring wells further from the pumping site, located in the mica-schist (F09, F07, F21), and in the granite (F22); and one shallow well located in the weathered rock (MF2)). These 10 wells are situated at different distances from the pumping site, which consists of three production wells (Pe, F31, and F29) (Figure 3c). A few monitoring wells have been recording weekly since 1991 . However, for this study, only water level fluctuations from 

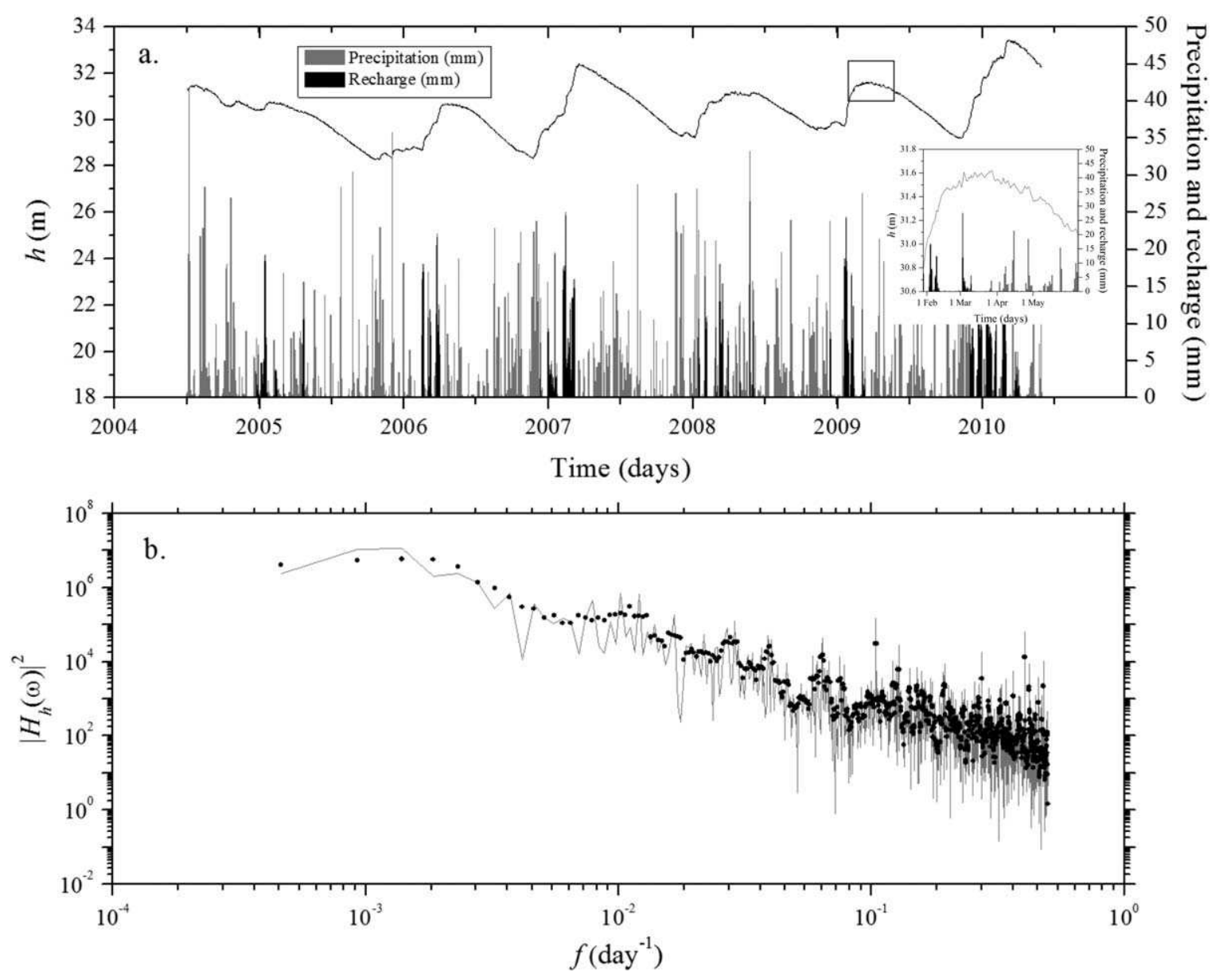

Figure 5. (a) Recharge and groundwater level fluctuations $(h)$ at monitoring well F07 as input and output functions, respectively. (b) Empiric transfer function (gray line) and regularized transfer function (black dots) for monitoring well F07 as a function of frequency $f$.

2003 to 2010 were considered, to ensure stationarity of the time series (Figure 4). Water levels are monitored continuously with pressure probes and sampled every $30 \mathrm{~s}$ to 10 min, depending on the measurement device, and compensated from the barometric pressure contribution. Every 2 months, the probes are compared with absolute manual measurements and recalibrated if necessary. All wells, except MF2, are recording tides which implies a dominant confined behavior. The MF2 monitoring well is sampling an unconfined compartment situated in weathered rock. Whereas in other fractured crystalline aquifers the water tables rise rapidly and significantly during and after precipitation events [e.g., Gburek and Folmar, 1999; Lee and Lee, 2000; Rodhe and Bockgard, 2006; Heppner et al., 2007; Praamsma et al., 2009], no rapid risings are detected at the Ploemeur site. This is confirmed by the weak cross-correlation between rainfall and groundwater level fluctuation.

[28] Time series of weather variables (i.e., daily precipitation, and potential evpotranspiration) were recorded at two meteorological stations over the above mentioned period. Data from the Lan Bihoue meteorological station (Météo-France), located $2.5 \mathrm{~km}$ north of the site, were used in this work, because they had been recorded over a longer period and were more complete. Gaps and errors in the series were supplemented with data from a secondary meteor- ological station located at the pumping site (Figure 3c). A soil storage volume of $250 \mathrm{~mm}$, determined from the soil thickness (average value $2 \mathrm{~m}$, from well logs and hand drilling) and field capacity (average value 23\%, determined in the laboratory), is used to calculate the aquifer recharge. Recharge occurs mainly between December and March (see Figure 4), with a mean annual value of $260 \mathrm{~mm}$ for the period 2003-2010, which represents $27 \%$ of the annual precipitation.

\subsection{Data Processing. Input and Output Signal}

[29] In order to reduce potential sources of nonlinearity coming from unsaturated zone processes, we use recharge at the bottom of the soil layer as input for the frequency domain analysis. However, recharge is generally difficult to estimate, since it is affected by many factors such as rainfall duration and intensity, vegetation, slope, soil properties and soil thickness, etc. Recent studies of aquifer recharge have demonstrated significant spatial and temporal variations in groundwater recharge rates [Scanlon et al., 2002]. In order to reproduce the equivalent groundwater behavior and compare the responses at different observation points, we used an approach based on the principle of an overflowing reservoir [e.g., Molenat et al., 1999; Jukic and DenicJukic, 2004], which is valid only if the surface runoff is 
limited. When the soil reservoir is full, this means that field capacity has been reached and recharge takes place. After dry periods, essentially in summer, the soil reservoir is replenished by precipitation and subsequently the aquifer is recharged (Figure 5a).

[30] The piezometric water level is used as output in the analysis. The data is processed in a four-step approach: (a) Gaps in raw data (i.e., recorded in the data logger) are interpolated, using linear interpolation when the gap length is shorter than $1 \mathrm{~h}$. (b) Tides in wells are fitted and removed using the t_tide MATLAB code [Pawlowicz et al., 2002]. (c) Daily data are extracted by applying a low-pass anti-aliasing filter, to restrict the bandwidth of the signal to periods above 2 days, and by down sampling (d) Gaps in the new daily data set are linearly reinterpolated and any long term trend is eliminated from the time series with a least-square linear regression (Figure 5a). The resulting time series are stationary, in the sense that the first and second moments, the mean and amplitude of the annual signal, respectively, do not vary with time (see Figure 4).

\subsection{Transfer Function Computation and Regularization}

[31] Spectrums are computed using a nonparametric method [Welch, 1967], which consists of dividing the time series data into overlapping segments, multiplying by Hamming windows, computing the spectrum of each segment with the fast Fourier transform, and then averaging the estimates. Small errors in measured data, noise in the system itself, or slight rounding errors in the numerical process, can result in large oscillations of the transfer function [ $\mathrm{Del}$ leur and Rao, 1971]. These oscillations are often suppressed through regularization carried out by filtering or by enforcing smoothness.

[32] Regularization can be applied to the input and/or output signal [e.g., Delleur and Rao, 1971; Neuman and de Marsily, 1976], the transfer function [e.g., Blank et al., 1971], or both [e.g., Daboczi, 1998; Long and Derickson, 1999]. Procedures for performing regularization include: moving average [e.g., Blank et al., 1971]; linear programming as used by Neuman and de Marsily [1976] and Dreiss [1989]; the Parzen-Rosenblatt window method (Kernel density estimation) [e.g., Manga, 1999]; the Hanning window method [e.g., Long and Derickson, 1999]; or geostatistical approaches [e.g., Fienen et al., 2006; Cirpka et al., 2007].

[33] Here, we used a Savitzky-Golay smoothing filter [Savitzky and Golay, 1964]. This kind of filter, also called a polynomial or least squares filter, performs much better than the standard moving average, which tends to filter out a significant portion of the signal at high frequencies, along with the noise [Orfanidis, 1996]. The Savitzky-Golay filter is optimal in the sense that it minimizes the least-squares error in fitting a polynomial to each frame of noisy data (Figure 5b).

\section{Results and Discussion}

\subsection{Transfer Functions}

[34] The computed transfer functions are plotted in Figure 6 for the wells located around the pumping site, (F20, F17, F19, F35, and F38), in Figure 7 for the wells located further from the pumping site, (F09, F07, F21, and F22), and in Figure 8 for the well representing weathered rock, (MF2). A general pattern, i.e., a flat section at low frequency, a decreasing section at intermediate frequency, and finally, different behaviors at high frequency are observed in all cases, which confirms that the fractured aquifer acts as a low-pass filter.

[35] For monitoring wells near to the pumping site (Figure 6 ), the amplitudes of the transfer functions are similar at low frequency, which means that they have similar discharge constant $(a)$ values. They also present similar characteristic times (break in the slope between low and mid frequency subsets). On the contrary, different behaviors (log-log slope) are observed in the high-frequency subset, with larger variability. In this case, the variability is largely related to the effect of pumping as discussed in the next chapter.

[36] The monitoring wells located further from the pumping site (Figure 7), have different amplitudes at low frequency, implying different apparent discharge constant values, as well as different characteristic times. At mid frequency, the transfer functions of F07 and F21 decrease linearly with frequency in the log-log scale, suggesting a simple linear model-like behavior. At high frequency, two of them (F09 and F22), show a different log-log slope after a second breakpoint, indicating the existence of a second temporal scaling regime.

[37] The transfer function for the monitoring well representing the weathered rock (MF2, $32 \mathrm{~m}$ depth) shows the same behavior as F09 and F22 (Figure 8). The second crossover point from mid to high frequency in these three wells (MF2, F09, and F22) ranges between $f \sim 0.010$ and 0.038 day $^{-1}$, i.e., $t_{f} \sim 26-100$ days.

\subsection{Impact of Pumping on Transfer Functions}

[38] Pumping affects the observation wells located close to the production wells, and introduces a relatively uniform signal in the water level record with a consequent impact on the frequency domain (Figure 6). This process has to be considered in order to avoid misinterpretation of the transfer functions in terms of physical parameters and system behavior. We evaluated the impact of pumping activities on transfer functions by superimposing a simulated drawdown signal on a piezometric level unaffected by pumping and considered as a reference. The effect of pumping is analyzed by comparing the transfer function of the obtained piezometric level with that of the reference piezometric level.

[39] A time series of water level fluctuations from a monitoring well located far from the pumping site and presumably unaffected by pumping (e.g., F07), is used as reference behavior, $h(t)$. Over this water level time series and assuming confined conditions and homogeneity, a pumping signal $s^{\prime}(t)$, including successive drawdown (subscript d) and recovery (subscript r) periods, is superimposed, $h^{\prime}(t)=h(t)+s^{\prime}(t)$, using the Theis model [Theis, 1935]

$$
s^{\prime}(t)=\frac{Q_{d}}{4 \pi T} W_{d}(u)+\frac{Q_{r}}{4 \pi T} W_{r}(u)
$$

$$
u=\frac{d^{2} S}{4 T t_{d, r}},
$$

where $u$ is a dimensionless time parameter; $Q$ is the pumping and recovering rate of the well $\left(\mathrm{m}^{3} \mathrm{~s}^{-1}\right) ; T$ and $S$ are 

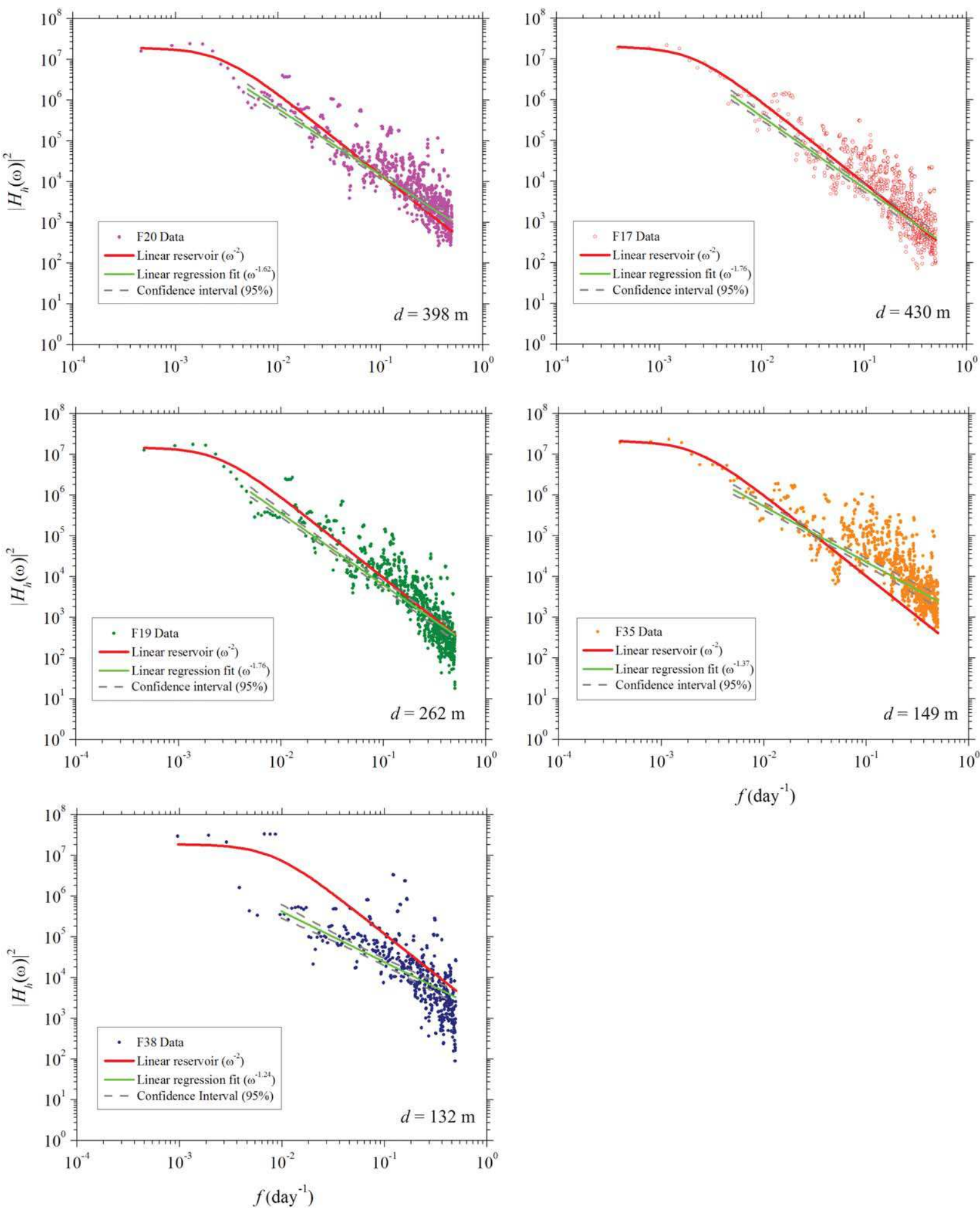

Figure 6. Empirical regularized transfer functions (symbols) and linear reservoir model fits at monitoring wells located around the pumping site: F20, F17, F19, F35, and F38. Linear regression fits and confidence intervals $(95 \%)$. Detailed information can be found in Table 1. $d$, mean distance from the pumping site.

the transmissivity and storativity of the aquifer around the well (from Le Borgne et al. [2006a]); $d$ is the distance from the pumping well to the observation point $(\mathrm{m}) ; t_{d, r}$ is the time since pumping and recovering periods began ( $\mathrm{s})$; and $W(u)$ is the "well function." Drawdown and recovery peri- ods are generated with the same amplitude and frequency as at the Ploemeur pumping site.

[40] The pumping impact is investigated for different pumping rates and distances from the pumping well, as illustrated in Figures $9 \mathrm{a}$ and $9 \mathrm{c}$, respectively. The main 

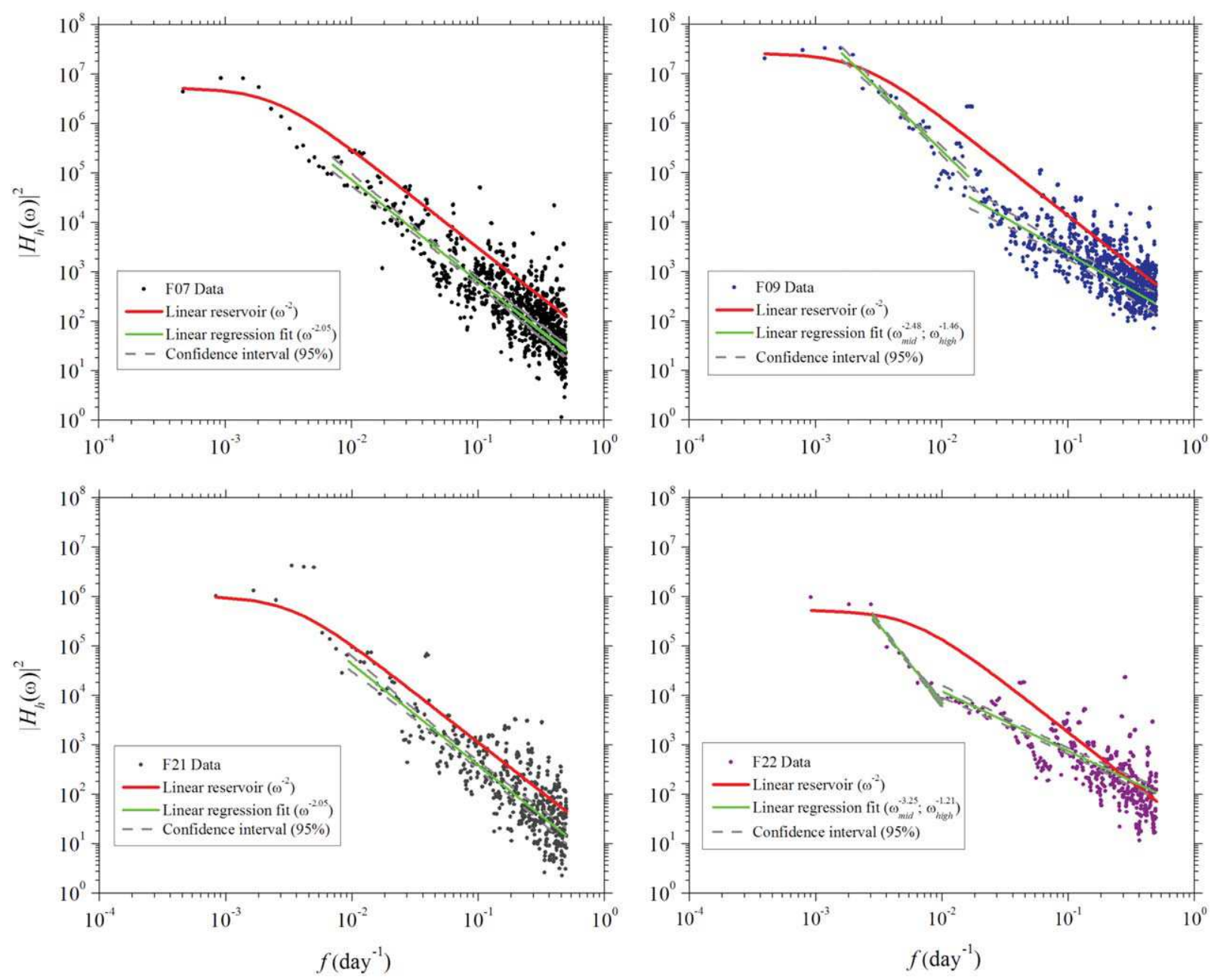

Figure 7. Empirical regularized transfer functions (symbols) and linear reservoir model fits at monitoring wells located further from the pumping site: F09, F07, F21, and F22. Linear regression fits and confidence intervals (95\%). Detailed information can be found in Table 1.

influence of pumping is to introduce a deviation from the linear behavior (characterizing the reference signal) at high frequency, i.e., for times less than 200 days, with log-log slopes decreasing at mid and high frequencies. The noise content (variability of the deviation from the linear behavior) is equivalent whatever the distance or pumping rate, and is directly related to the frequency content of the pumping signal. An equivalent noise content is observed between the synthetic model and field observations (e.g., F35 and F38 monitoring wells, see Figure 6). The dependency of the transfer function slope, at mid and high frequencies, on the pumping rate and distance is illustrated in Figures $9 \mathrm{~b}$ and $9 \mathrm{~d}$, respectively. The method used to compute the slope is described in section 4.4. When the pumping rate increases, the slope decreases until it reaches an asymptotic value $(\beta=0.4)$ (Figure $9 \mathrm{~b})$. Reducing the distance between the observation wells and the pumping wells also induces a decrease in log-log slope.

[41] No remarkable changes are detected for the characteristic response time (transition time between high and mid frequency subsets), or in the asymptotic behavior at low frequency. Based on this analysis, we deduce that the monitoring wells affected by pumping are mostly disturbed

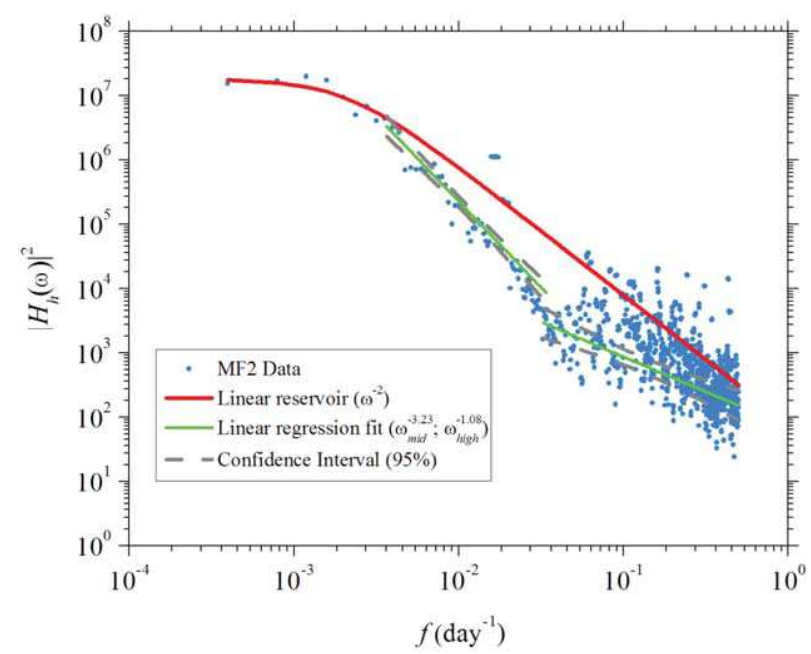

Figure 8. Empirical regularized transfer function (symbols) and linear reservoir model fit at monitoring well representative of the weathered rock, MF2. Linear regression fits and confidence intervals (95\%). Detailed information can be found in Table 1 . 

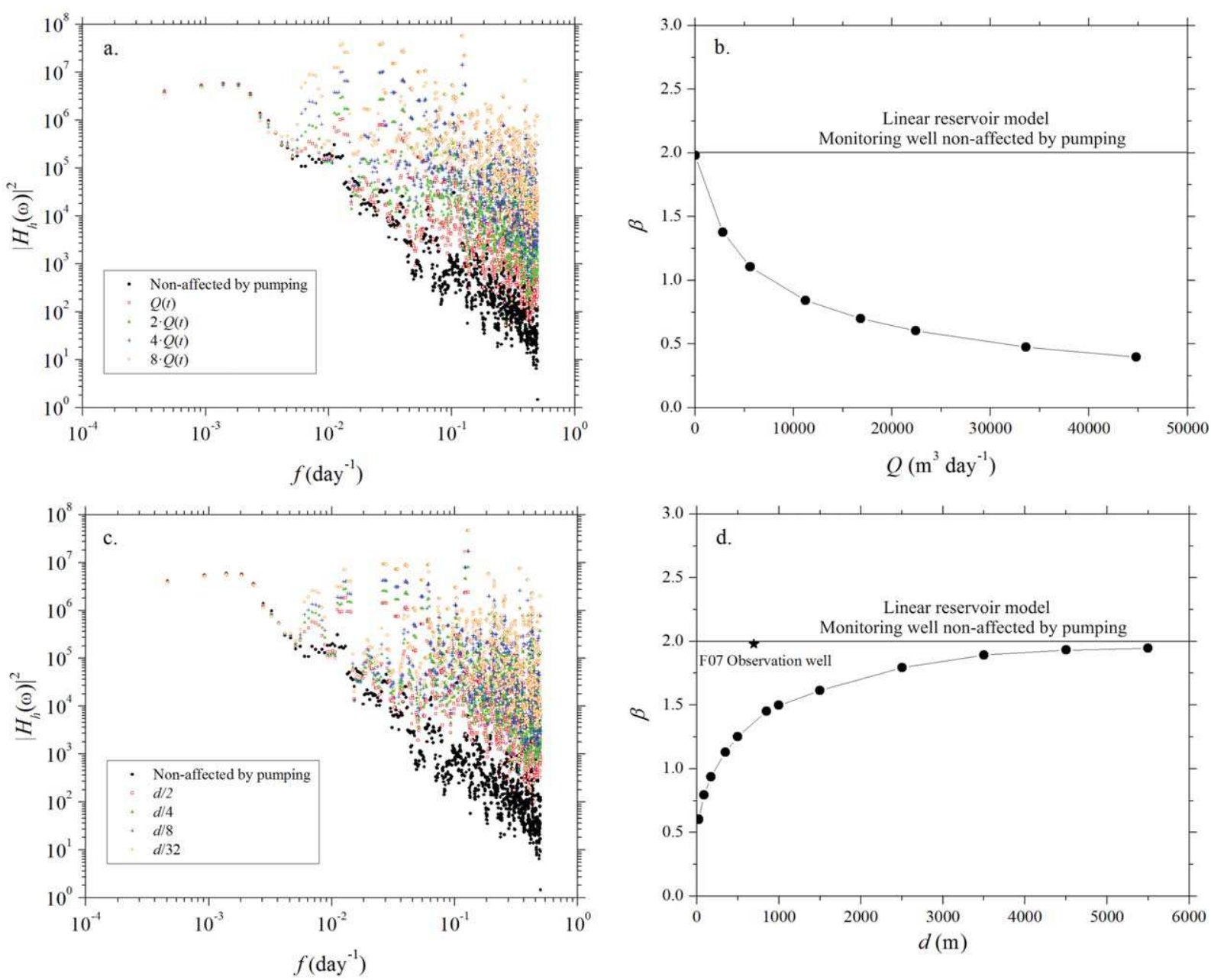

Figure 9. (a) Pumping impact on the transfer functions for different multiplicative factors of pumping rate function, $Q(t) . Q=2800 \mathrm{~m}^{3}$ day $^{-1}$ at the Ploemeur site for the period 2003-2010. (b) Mean annual pumping rate impact on transfer function slope, $\beta$. (c) Pumping impact on the transfer functions at varying distances between observation and pumping well, $d . d=640 \mathrm{~m}$ for the baseline case, monitoring well F07. (d) Distance impact on transfer function slope, $\beta$.

at high frequency. Hence, the transfer function of the wells affected by pumping can be used to estimate the aquifer response characteristic times and low-frequency amplitude, but not the high-frequency log-log slopes.

\subsection{Impact of Recharge Estimation on Transfer Functions}

[42] As discussed above, the estimation of recharge at the bottom of the soil horizon is uncertain. Soil storage was best estimated around $250 \mathrm{~mm}$ from a priori field data, leading to an annual recharge around $260 \mathrm{~mm}$. In this section, we investigate the impact of this recharge estimation uncertainty on the transfer function estimation. Soil storage is varied from $166 \mathrm{~mm}$ to $332 \mathrm{~mm}$ (Figure 10a), which implies a range of mean annual recharge between 169 and $282 \mathrm{~mm}$. Variation of the mean annual recharge value produces slight changes in the asymptotic behavior at low frequency (i.e., discharge constant or recession coefficient), implying a modification in the long term mass balance. The general shape of the transfer function keeps unchanged, with similar decreasing slopes (Figure 10b). This result confirms that the observed nonclassical log-log slopes for some observation wells are not influenced by uncertainties in the computation of input recharge, and thus correspond to an intrinsic property of the aquifer.

\subsection{Temporal Scaling of Hydraulic Response to Recharge}

[43] The dependency of the spectral amplitude on frequency, as expressed by the mid- and high-frequency loglog slope, quantifies the contribution of the different structures and flow lines to the hydraulic response to recharge in a given observation well (see Figure 1). These different structures and flow lines are associated with different characteristic response times, related to their length and diffusivity. Hence, the distribution of spectral amplitude with frequency reflects the flow geometry and the distribution of preferential flow paths. The scaling properties of the frequency domain are analyzed by applying a linear least squares regression to estimate the transfer function log-log slope at mid and high frequency. The fit of the log-log slope is performed in ranges of frequency where it is 

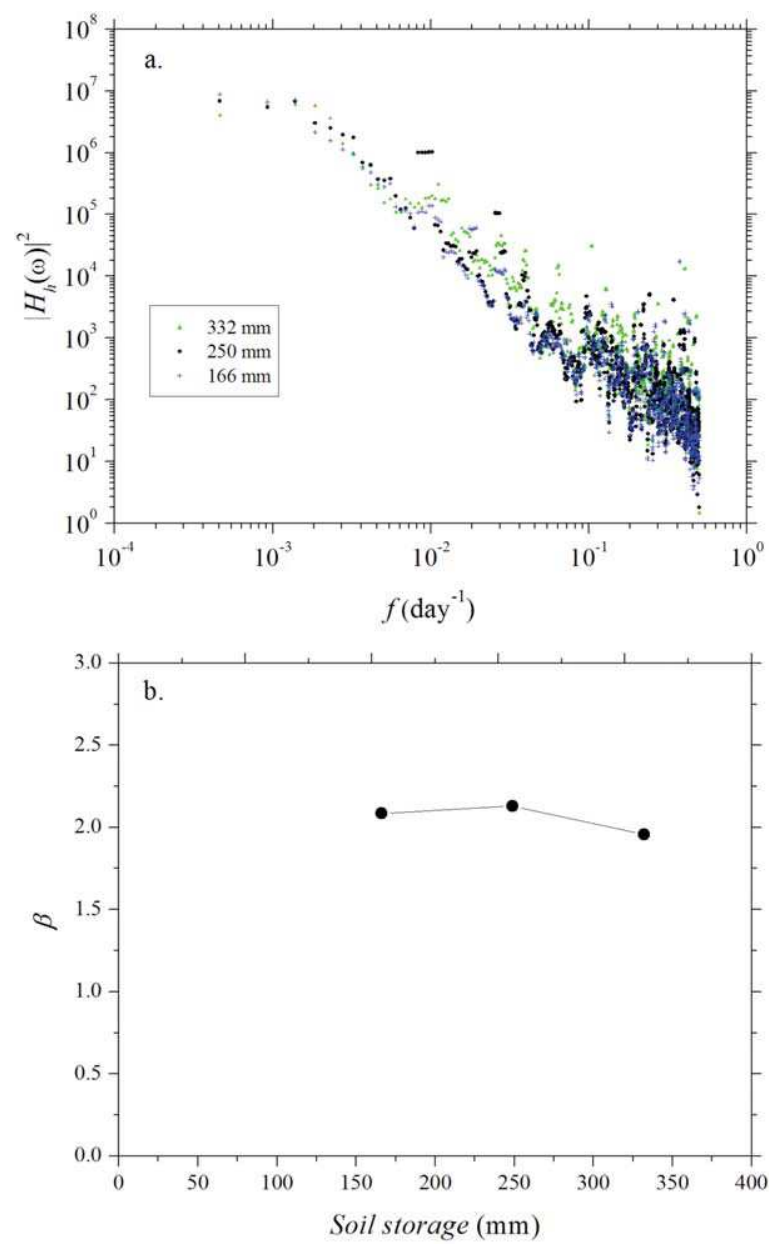

Figure 10. (a) Sensitivity analysis of soil storage parameter and recharge function uncertainty on the transfer function estimation at monitoring well F07. (b) Soil storage parameter and recharge function impact on the transfer function slope, $\beta$. Legend includes soil storage value.

approximately stable, i.e., in between breakpoints (Figures 6-8). A logarithmic frequency discretization is included in the process, in order to give the same weight to all logarithmic cycles, since most of the data is concentrated at high frequency. Furthermore, confidence intervals at $95 \%$ are computed for the fitted parameters (Table 1). Fitting is carried out for all monitoring wells, including those located close to the pumping site (affected by pumping), to show how pumping produces a reduction in the transfer function log-log slope at mid and high frequency (Table 1).

[45] The log-log slope $\beta$ values for monitoring wells located close to the pumping site, and clearly affected by pumping (i.e., F20, F17, F19, F35, and F38), range from 1.8 to 1.2 , with the smallest exponents corresponding to those wells that are most affected by pumping. As discussed in section 4.2, these slopes are related to the effect of pumping and not to recharge processes. The monitoring wells located further from the pumping site can be divided into two subgroups: F07 and F21, which have an exponent $\beta \approx 2$ over the full range of frequencies; and F09 and F22, along with MF2 (representative of weathered rock), which have an exponent $\beta>2$ at mid frequency, and $1.1<\beta<$ 1.5 after the second breakpoint (Table 1). Note that this behavior differs from that observed by Molenat et al. [1999] and Trinchero et al. [2011], who reported a slope $\beta=0$, which they attributed to the existence of preferential flow paths.

[46] The different behaviors discussed above can be explained in terms of recharge mechanisms. The fact that the transfer functions from some monitoring wells (e.g., F07 and F21) can be reproduced by a linear reservoir model suggests that the aquifer may behave, on a large scale, as an equivalent homogeneous one. However, the observation of a slope reduction $(\beta<2)$ at high frequency for wells F09, F22, and MF2 suggests the existence of faster recharge processes, which may be attributed to preferential flow paths of different diffusivities (see Figure 1). The fact that the slope is larger than zero indicates that not all flow paths contribute with the same strength. The amplitude of the response decreases with frequency. Each frequency $f$ can be associated with a time scale $t_{f}=1 / f$. Hence, the fastest flow paths, associated with the high frequency, are more attenuated than the slower flow paths, associated with intermediate frequencies.

\subsection{Spatial Scaling of Hydraulic Parameters}

[47] The frequency domain analysis can be used to quantify effective, large scale, hydraulic properties (storage coefficient, transmissivity), as long as conceptual models are consistent with the empirical transfer functions, as discussed in the previous section. In our case, as shown in Figures 6-8, the linear reservoir model is consistent with transfer functions at low and mid frequency, with the exception of monitoring wells F09, F22, and MF2, which behave differently from classic models, as discussed in the previous section. The two fitting parameters (by least-squares fit method) of the linear model (equation (8)), which define the low-frequency amplitude $1 / a^{2}$ and the characteristic response time $t_{L}$, are used to estimate the transmissivity, $T=a L^{2} / 3$, and the storage coefficient, $S=a t_{L}$.

Table 1. Fitted Slope $(\beta)$ by Linear Least Squares Regression and Confidence Intervals (95\%) at Each Monitoring Well for Regularized TFs ${ }^{\mathrm{a}}$

\begin{tabular}{lccc}
\hline & & \multicolumn{2}{c}{$\begin{array}{c}\text { Confidence Interval } \\
(95 \%)\end{array}$} \\
\cline { 3 - 4 } Monitoring well & & Lower & Upper \\
\hline $\begin{array}{l}\text { Close to pumping site } \\
\quad \text { (affected by pumping) }\end{array}$ & & & \\
F20 & 1.60 & 1.75 & 1.50 \\
F17 & 1.75 & 1.85 & 1.65 \\
F19 & 1.75 & 1.85 & 1.65 \\
F35 & 1.35 & 1.50 & 1.25 \\
F38 & 1.25 & 1.40 & 1.05 \\
Far from pumping site & & & \\
$\quad$ (nonaffected by pumping) & & & \\
F07 & 2.05 & 2.10 & 1.90 \\
F09 & $2.50 / 1.45$ & $2.70 / 1.70$ & $2.25 / 1.20$ \\
F21 & 2.05 & 2.20 & 1.90 \\
F22 & $3.25 / 1.20$ & $3.45 / 1.35$ & $3.00 / 1.10$ \\
Weathered rock & & \multicolumn{2}{c}{} \\
$\quad$ nonaffected by pumping) & & & \\
MF2 & $2.65 / 1.10$ & $2.95 / 1.45$ & $2.40 / 0.75$ \\
\hline
\end{tabular}

${ }^{\mathrm{a}}$ Monitoring wells with two behaviors include fits at mid- $\left(\omega_{\text {mid }}\right)$ and high-frequency $\left(\omega_{\text {high }}\right), \omega_{\text {mid }} / \omega_{\text {high. }}$. See Figures 6-8. 


\section{JIMÉNEZ-MARTÍNEZ ET AL.: TEMPORAL AND SPATIAL SCALING IN FRACTURED AQUIFERS}

[48] The estimation of transmissivity requires definition of the length of the aquifer system $L$. This latter can be difficult to estimate, especially for fractured systems. At the Ploemeur site, the regional structure providing most recharge is thought to be the fractured zone located at the contact between granite and mica-schist [Touchard, 1999; Ruelleu et al., 2010; Leray et al., 2012]. The geometry of this zone (Figure 3e) has been inferred by applying geological arguments and gravity measurements [Ruelleu et al., 2010]. Based on these studies, the estimated aquifer length is about $2700 \mathrm{~m}$. We then assessed the impact of the uncertainty associated with this parameter by testing two possible values of $L: 2000$ and $3000 \mathrm{~m}$ (Table 2, Figure 11a). The average transmissivity for these different aquifer lengths is $10^{-2} \mathrm{~m}^{2} \mathrm{~s}^{-1}$, ranging a factor two. In all cases, the large-scale transmissivity values for this aquifer are very high compared to those commonly measured in crystalline rocks [e.g., Clauser, 1992; Martinez-Landa and Carrera, 2005; Hsieh, 1998; Shapiro, 2003], which is consistent with the exceptional productivity of this aquifer. The obtained values are in good agreement with those derived by Le Borgne et al. [2006a], and recently by Leray et al. [2012] by inverse modeling of groundwater age data.

[53] Storage coefficient values are estimated from the characteristic response time $t_{L}$ and thus are not subject to the uncertainty associated with aquifer length. The estimated values (Table 2, Figure 11b) show a relatively small variability (one order of magnitude), with an average value of $10^{-2}$, which may seem relatively large for a fractured aquifer. However, this value is similar to the storage coefficient values obtained by other authors from large-scale integrative procedures, in weathered crystalline rock [e.g., Maréchal et al., 2006]. Hence, on a regional scale, the contribution of the weathered reservoir may explain the large values obtained (see Figure 1).

[54] Scale effects in the hydraulic properties (e.g., storage coefficient, transmissivity) are analyzed by comparing the results from frequency domain analysis with those derived from three different field techniques involving dis- tinct spatial and temporal scales of investigation [ $L e$ Borgne et al., 2006a]: single-borehole flowmeter experiments, cross-borehole flowmeter experiments and longterm pumping tests, along with those obtained from ground deformation by GPS measurements [Moreau et al., 2006].

[55] Although there are some uncertainties related to the estimation of aquifer length, the general trend for the evolution of transmissivity with scale is a reduction of variability, and convergence at large scale toward the largest transmissivity values measured at small scale (Figure 11a). The small difference in the average transmissivity estimates between long-term pumping tests and frequency domain analysis suggests that a homogenization scale has been reached [e.g., Clauser, 1992; Rovey and Cherkauer, 1995]. This suggests that the large transmissive fractures are well connected on a large scale and thus control the long-term hydraulic behavior. A similar increase in transmissivity with scale for fractured media has been observed by e.g., Martinez-Landa and Carrera [2005] and Illman [2006]. However, a decrease in transmissivity can also be observed for sites where the large transmissivity fractures are not well connected (e.g., Mirror Lake site, Hsieh [1998], Shapiro [2003]; Unita Basin of Utah, Hsieh [1998]). Thus, our results confirm that the effects of scale on transmissivity depend on the connectivity of the fracture network.

[56] The trend in the evolution of storage coefficient with scale is a significant increase, with a reduction of variability (Figure 11b). An explanation for this scaling can be proposed based on sampling of the different compartments that contribute to storage from the different techniques. Flowmeter and pumping test experiments tend to preferentially capture low storativity features, which respond faster to hydraulic perturbations. Vertical deformation from GPS measurements provides integrated storage information in confined conditions [Moreau et al., 2006]. The frequency domain analysis quantifies the effective basin-wide processes, including the weathered compartments, which may have a large storage. Studies reporting the effects of spatial

Table 2. Fitted Linear Reservoir Model Parameters at Each Monitoring Well ${ }^{\mathrm{a}}$

\begin{tabular}{|c|c|c|c|c|c|}
\hline \multirow[b]{3}{*}{ Monitoring Well } & \multicolumn{2}{|c|}{ Linear Reservoir } & \multicolumn{3}{|c|}{ Effective Hydraulic Parameters } \\
\hline & \multirow[b]{2}{*}{$t_{L}$ (day) } & \multirow[b]{2}{*}{$a\left(\right.$ day $\left.^{-1}\right)$} & \multirow[b]{2}{*}{$S^{\mathrm{b}}(-)$} & \multicolumn{2}{|c|}{$T^{\mathrm{c}}\left(\mathrm{m}^{2} \mathrm{~s}^{-1}\right)$} \\
\hline & & & & $L=2000 \mathrm{~m}$ & $L=3000 \mathrm{~m}$ \\
\hline \multicolumn{6}{|c|}{ Close to pumping site (affected by pumping) } \\
\hline F20 & 58 & $2.2510^{-4}$ & $1.3110^{-2}$ & $4.2310^{-3}$ & $9.5210^{-3}$ \\
\hline F17 & 76 & $2.2110^{-4}$ & $1.6810^{-2}$ & $4.1510^{-3}$ & $9.3510^{-3}$ \\
\hline F19 & 64 & $2.5610^{-4}$ & $1.6510^{-2}$ & $4.8210^{-3}$ & $1.0810^{-2}$ \\
\hline F35 & 74 & $2.1510^{-4}$ & $1.1510^{-2}$ & $4.0410^{-3}$ & $9.0910^{-3}$ \\
\hline F38 & 20 & $2.3010^{-4}$ & $4.6310^{-3}$ & $4.3210^{-3}$ & $9.7210^{-3}$ \\
\hline \multicolumn{6}{|c|}{ Far from pumping site (nonaffected by pumping) } \\
\hline F07 & 63 & $4.5610^{-4}$ & $2.8710^{-2}$ & $7.0310^{-3}$ & $1.5810^{-2}$ \\
\hline F09 & $-{ }^{d}$ & $-{ }^{d}$ & $-{ }^{\mathrm{d}}$ & $-{ }^{d}$ & $-{ }^{d}$ \\
\hline $\mathrm{F} 21$ & 49 & $9.7510^{-4}$ & $4.7710^{-2}$ & $1.8310^{-2}$ & $4.1210^{-2}$ \\
\hline F22 & $-{ }^{\mathrm{d}}$ & $-{ }^{\mathrm{d}}$ & $-{ }^{\mathrm{d}}$ & $-{ }^{d}$ & $-{ }^{\mathrm{d}}$ \\
\hline \multicolumn{6}{|c|}{ Weathered rock (nonaffected by pumping) } \\
\hline MF2 & $-{ }^{d}$ & $-{ }^{d}$ & $-{ }^{\mathrm{d}}$ & $-{ }^{\mathrm{d}}$ & $-{ }^{d}$ \\
\hline
\end{tabular}

${ }^{a}$ Effective hydraulic parameters, storage coefficient $(S)$ and transmissivity $(T)$, values calculated from linear reservoir model.

${ }^{\mathrm{b}} S$ computed from equation (9).

${ }^{\mathrm{c}} T$ computed from equation (10)

${ }^{\mathrm{d}}$ Values not computed due to the inconsistency with the current models. 
a.

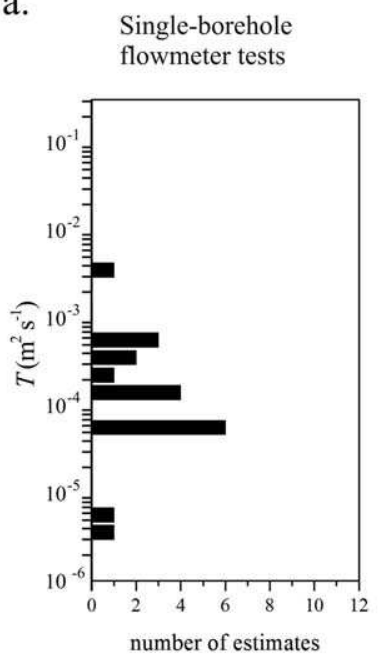

b.

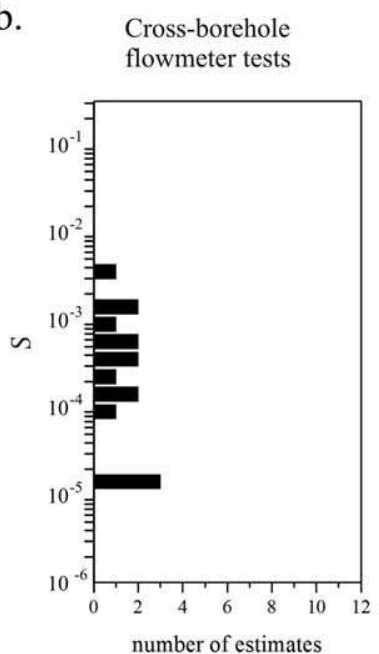

Cross-borehole

flowmeter tests

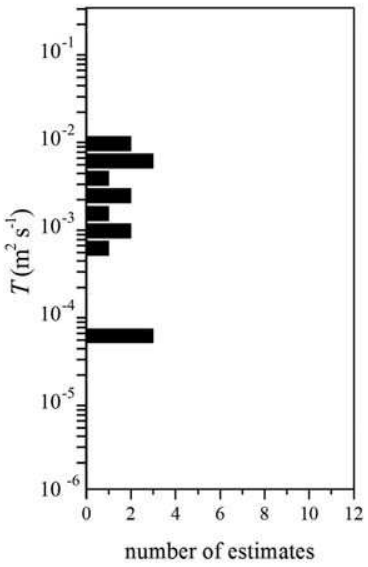

Long-term

pumping tests

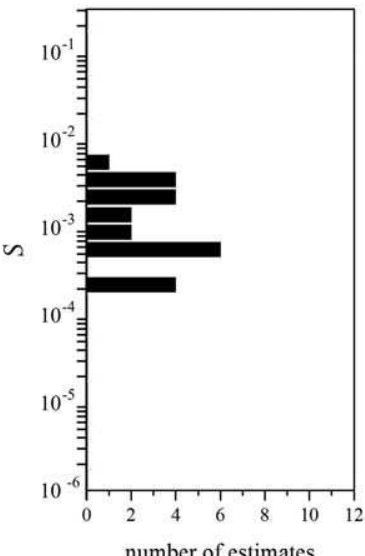

Long-term

pumping tests

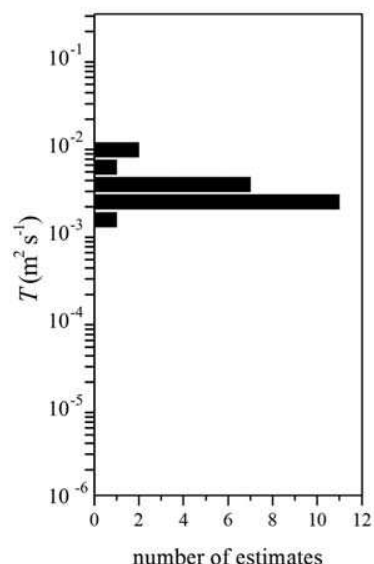

Ground deformation GPS measurements

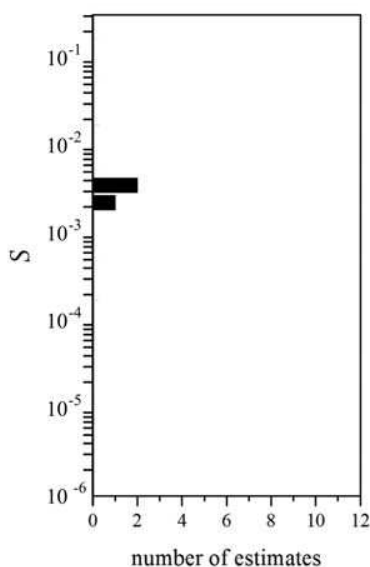

Frequency domain analysis

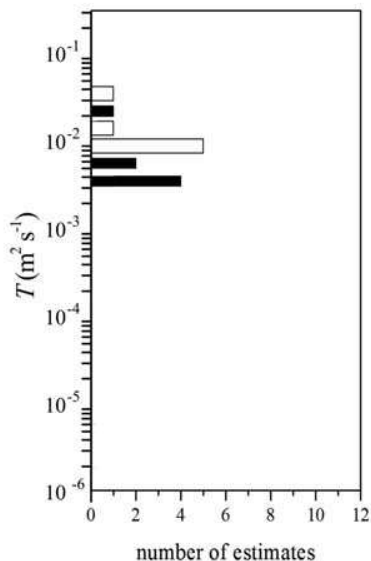

Frequency domain analysis

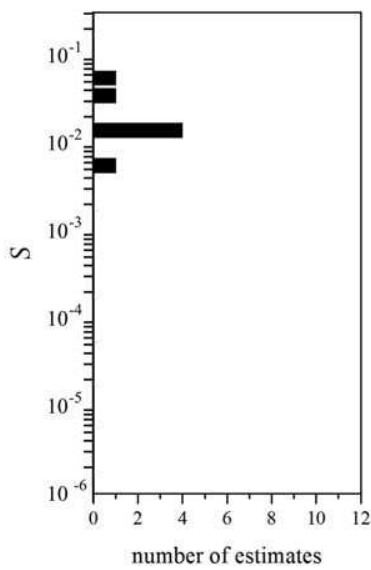

Figure 11. Storage coefficient (a) and transmissivity (b) estimates from field techniques (single-borehole flowmeter, cross-borehole flowmeter and long-term pumping tests by Le Borgne et al. [2006a]), from ground deformation by GPS measurements [Moreau et al., 2006], and frequency domain analysis. Plots are organized according to increasing observation scale from left to right. Two different aquifer lengths $L$ are used to compute transmissivity values from the frequency domain analysis (equation (10)): $2000 \mathrm{~m}$ (black bars); $3000 \mathrm{~m}$ (white bars).

scale on the storage coefficient are scarce. Vesselinov et al., [2001] and subsequently Illman [2005] showed an increase in porosity with observation scale by comparing singleborehole and cross-borehole porosity estimates.

[57] Hydraulic diffusivities $D=T / S$ in fractured media may typically range from $10^{-2}$ to $10 \mathrm{~m}^{2} \mathrm{~s}^{-1}$, and are very valuable information for mapping fracture connectivity during pumping tests [Knudby and Carrera, 2006]. Indeed, diffusivity for conductive fractures is $1-10 \mathrm{~m}^{2} \mathrm{~s}^{-1}$, and reaching $10^{2} \mathrm{~m}^{2} \mathrm{~s}^{-1}$ for extremely opened fractures. Boreholes are generally drilled in conductive structures, therefore, cross-borehole tests sample active fractures around the well, which are highly diffusive. A few wells, however, show low diffusivities below $1 \mathrm{~m}^{2} \mathrm{~s}^{-1}$. Connected fractures are first solicited during pumping tests (e.g., long-term pumping tests) before pressure reaches the matrix, leading to lower diffusivities around $10 \mathrm{~m}^{2} \mathrm{~s}^{-1}$. For frequency domain analysis, the equivalent hydrological system is mainly solicited at seasonal time scales and conductive fractures represent a limited part of the total volume, with diffusivities around $10^{-1} \mathrm{~m}^{2} \mathrm{~s}^{-1}$. Therefore, a decrease of the average hydraulic diffusivity with the observation scale is observed (Figure 12).

[58] The hydraulic diffusivities can be used to quantify the distribution of characteristic hydraulic diffusion times $t_{c}=L^{2} / D$. The characteristic times $t_{c}$ calculated at small scale (i.e., from cross-borehole flowmeter tests) range from 1 to 100 days approximately. It corresponds to the range of frequencies where unconventional temporal scaling is observed (Figures 7 and 8), which may be related to the variability of small-scale diffusivity. However, at this stage, it is not possible to determine if the observation well is locally connected with preferential flow paths or to main regional permeable structures in the recharge process (see Figure 1). 

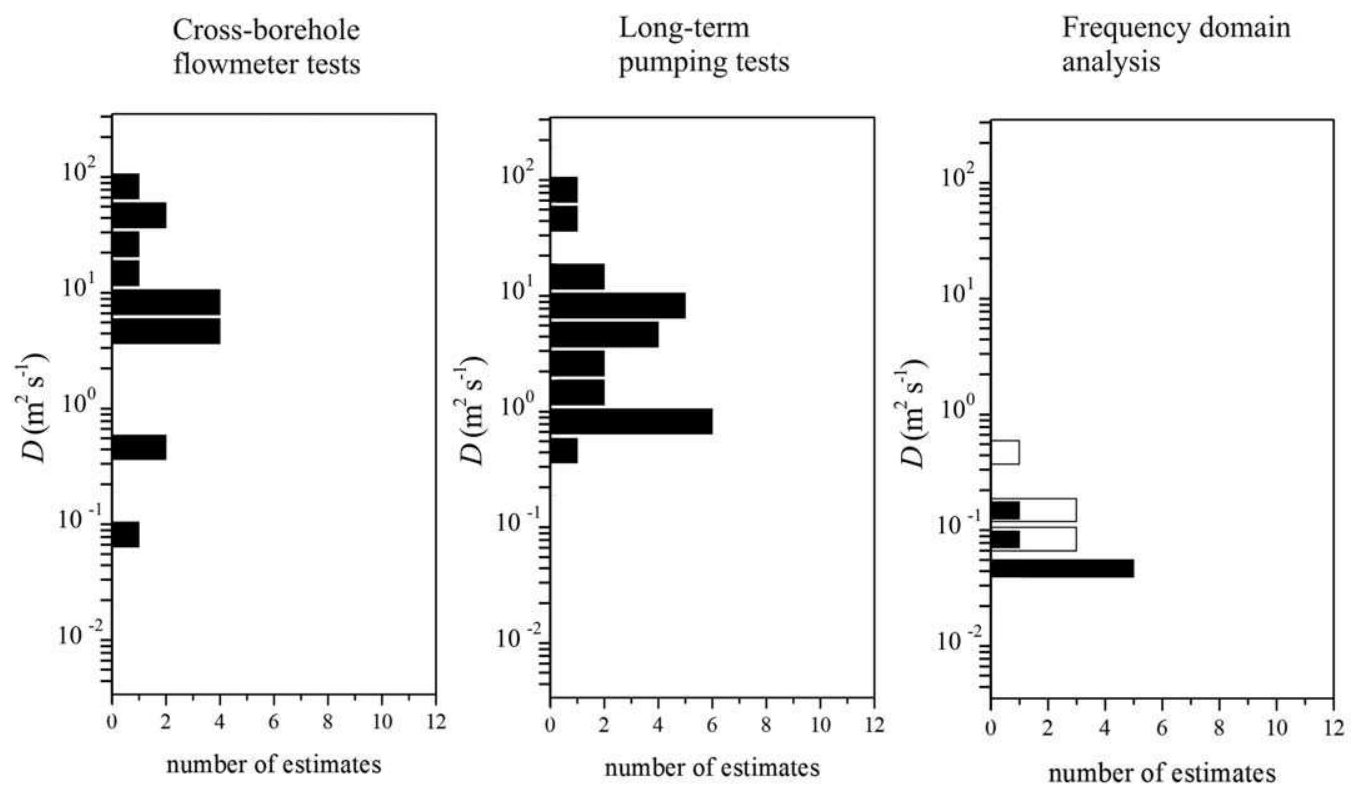

Figure 12. Hydraulic diffusivity estimates from field techniques (cross-borehole flowmeter and longterm pumping tests by Le Borgne et al. [2006a]), and frequency domain analysis. Plots are organized according to increasing observation scale from left to right. Two different aquifer lengths $L$ are used to compute diffusivity values from the frequency domain analysis: $2000 \mathrm{~m}$ (black bars); $3000 \mathrm{~m}$ (white bars).

\section{Conclusions}

[59] Investigation of the hydraulic behavior of a fractured aquifer over a wide range of time scales, through a frequency domain analysis, reveals the variability of the recharge processes in these complex systems. The contribution of different hydrogeological structures to the hydraulic response to recharge is indicated by the dependency of the transfer function amplitude on frequency. The fact that, for some wells, the transfer functions follow a linear scaling $(\beta=2)$ suggests that the fractured aquifer may behave like an equivalent homogenous one at large scale. On the contrary the slope reduction $(1.1<\beta<1.5)$ at high frequency, for some other monitoring wells, is attributed to the existence of preferential flow paths. Preferential flow paths have been previously associated with zero log-log slope, $\beta$ $=0$, implying that the system response is the same for a range of frequencies [Molenat et al., 1999, Trinchero et al., 2011]. Our result suggests that heterogeneity can induce nonzero temporal scalings, which may be related to the small-scale variability of hydraulic diffusivities.

[60] The effects of scale on key hydraulic parameters can be investigated by comparing the large-scale hydraulic parameter estimates with those obtained from methods with different observation scales. A general increase of both transmissivity and storage coefficient with scale is observed. The average transmissivity appears to converge toward a stable value, close to the largest small-scale transmissivity. In contrast, the storage coefficient estimates appear to consistently increase with scale. This effect may be explained by the contribution of weathered rock, which has a larger porosity than the deep fractures.

[61] Further investigations are needed to improve our knowledge of hydraulic response to recharge in fractured aquifers. In particular, the development of double and mul- ticontinuum models (permeability/porosity) in the frequency domain may be a means to model the anomalous temporal scaling observed at high frequencies.

[62] Acknowledgments. This work has been developed in the framework of the project CLIMAWAT (Adapting to the Impacts of Climate Change on Groundwater Quantity and Quality), EU-RDF INTERREG IVA France (Channel)-England program. Gratitude is expressed to SOERE-H ${ }^{+}$(National Network of Hydrogeological Sites). We are grateful to Nicolas Lavenant and Jean Pierre Caudal for technical support.

\section{References}

Bear, J. (1979), Hydaulics of Groundwater, 569 pp., McGraw-Hill, New York.

Becker, M. W., and A. M. Shapiro (2003), Interpreting tracer breakthrough tailing from different forced-gradient tracer experiment configurations in fractured bedrock, Water Resour. Res., 39(1), 1024, doi:10.1029/ 2001WR001190.

Besbes, M., and G. de Marsily (1984), From infiltration to recharge: Use of a parametric transfer function, J. Hydrol., 74, 271-293.

Blank, D., J. Delleur, and A. Giorgini (1971), Oscillatory kernel functions in linear hydrologic models, Water Resour. Res., 7, 1102-1117.

Bockgard, N., and A. Niemi (2004), Role of rock heterogeneity on lateral diversion of water flow at the soil-rock interface, Vadose Zone J., 3, 786795

Bonnet, E., O. Bour, N. E. Odling, P. Davy, I. Main, P. Cowie, and B. Berkowitz (2001), Scaling of fracture systems in geological media, Rev. Geophys., 39(3), 347-383.

Bour, O., and P. Davy (1997), Connectivity of random fault networks following a power law fault length distribution, Water Resour. Res., 33(7), $1567-1583$.

Bour, O., P. Davy, C. Darcel, and N. Odling (2002), A statistical scaling model for fracture network geometry, with validation on a multiscale mapping of a joint network (Hornelen Basin, Norway), J. Geophys. Res., 107(B6), 2113, doi:10.1029/2001JB000176.

Clauser, C. (1992), Permeability of crystalline rock, Eos Trans. AGU, 73(21), 237-238.

Cirpka, O. A., M. N. Fienen, M. Hofer, E. Hoehn, A. Tessarini, R. Kipfer, and P. K. Kitanidis (2007), Analyzing bank filtration by deconvoluting time series of electric conductivity, Ground Water, 45(3), 318-328. 
Daboczi, T. (1998), Nonparametric identification assuming two noise sources: A deconvolution approach, IEEE Trans. Instrum. Measure., 47, 828-832.

Day-Lewis, F. D., P. A. Hsieh, and S. M. Gorelick (2000), Identifying fracture-zone geometry using simulated annealing and hydraulic-connection data, Water Resour. Res., 36(7), 1707-1721, doi:10.1029/ 2000WR900073.

Day-Lewis, F. D., J. W. Lane Jr., J. M. Harris, and S. M. Gorelick (2003), Time-lapse imaging of saline-tracer transport in fractured rock using difference-attenuation radar tomography, Water Resour. Res., 39(10), 1290, doi:10.1029/2002WR001722.

de Dreuzy, J.-R., P. Davy, and O. Bour (2002), Hydraulic properties of twodimensional random fracture networks following power law distributions of length and aperture, Water Resour. Res., 38(12), 1276, doi:10.1029/ 2001WR001009.

de Dreuzy, J.-R., P. Davy, J. Erhel, J. de Brémond d'Ars (2004), Anomalous diffusion exponents in continuous 2D multifractal media, Phys. Rev. E, 70, 016306

Delleur, J. W., and R. A. Rao (1971), Linear systems analysis in hydrology: the transform approach, kernel oscillations and the effect of noise, in Systems Approach in Hydrology, pp. 116-142, Water Resources Publ., Fort Collins, Colo.

Dewandel, B., J. C. Maréchal, O. Bour, B. Ladouche, S. Ahmed, S. Chandra, and H. Pauwels (2012), Upscaling and regionalizing hydraulic conductivity and effective porosity at weathered scale in deeply weathered crystalline aquifers, J. Hydrol., 416-417, 83-97.

Dreiss, S. J. (1989), Regional scale transport in a karst aquifer: 2. Linear systems and time moment analysis, Water Resour. Res., 25(1), 126-134.

Duffy, C. J., L. W. Gelhar, and P. J. Wierenga (1984), Stochastic analysis of agricultural watersheds, J. Hydrol., 69, 145-162.

Erskine, A. D., and A. Papaioannou (1997), The use of aquifer response rate in the assessment of groundwater resources, J. Hydrol., 202, 373-391.

Fienen, M. N., J. Luo, and P. K. Kitanidis (2006), A Bayesian geostatistical transfer function approach to tracer test analysis, Water Resour. Res., 42, W07426, doi:10.1029/2005WR004576.

Gburek, W. J., and G. J. Folmar (1999), A ground water recharge field study: Site characterization and initial results, Hydrol. Process., 13, 2813-2831.

Gelhar, L. W. (1974), Stochastic analysis of phreatic aquifer, Water. Resour. Res., 10(3), 539-545.

Gelhar, L. W. (1993), Stochastic Subsurface Hydrology, Prentice-Hall, Upper Saddle River, N. J.

Gelhar, L. W., and J. L. Wilson (1974), Ground-water quality modeling, Ground Water, 12, 399-408.

Gleeson, T., K. Novakowski, and T. K. Kyser (2009), Extremely rapid and localized recharge to a fractured rock aquifer, J. Hydrol., 376, 496-509.

Gustafson, G., and J. Krásný (1994), Crystalline rock aquifers: their occurrence, use and importance, Hydrogeol. J., 2(2), 64-75.

Guyonnet, D., S. Mishra, and J. McCord (1993), Evaluating the volume of porous medium investigated during slug tests, Ground Water, 31(4), 627-633.

Heppner, C., J. Nimmo, G. Folmar, W. Gburek, and D. Risser (2007), Multiple-methods investigation of recharge at a humid-region fractured rock site, Pennsylvania, USA, Hydrogeol. J., 15(5), 915-927.

Hsieh, P. A. (1998), Scale effects in fluid flow through fractured geologic media, in Scale Dependence and Scale Invariance in Hydrology, edited by G. Sposito, pp. 335-353, Cambridge Univ. Press, New York.

Hubbard, S., and N. Linde (2011), Hydrogeophysics, in Treatise in Water Science, pp. 401-434, Elsevier, Amsterdam.

Illman, W. A. (2005), Type curve analyses of pneumatic single-hole tests in unsaturated fractured tuff: Direct evidence for a porosity scale effect, Water Resour. Res., 41, W04018, doi:10.1029/2004WR003703.

Illman, W. A. (2006), Strong evidence of directional permeability scale effect in fractured rock, J. Hydrol., 319(1-4), 227-236.

Illman, W. A., X. Liu, S. Takeuchi, T.-C. J. Yeh, K. Ando, and H. Saegusa (2009), Hydraulic tomography in fractured granite: Mizunami Underground Research site, Japan, Water Resour. Res., 45, W01406, doi:10.1029/2007WR006715

Jin, M., and C. J. Duffy (1994), Spectral and bispectral analysis for singleand multiple-input nonlinear phreatic aquifer systems, Water Resour. Res., 30(7), 2073-2095.

Jukic, D., and V. Denic-Jukic(2004), A frequency domain approach to groundwater recharge estimation in karst, J. Hydrol., 289, 95-110.

Knudby, C., and J. Carrera (2006), On the use of apparent hydraulic diffusivity as an indicator of connectivity, J. Hydrol., 329, 377-389.
Le Borgne, T., O. Bour, J.-R. de Dreuzy, P. Davy, and F. Touchard (2004), Equivalent mean flow models for fractured aquifers: insights from a pumping tests scaling interpretation, Water Resour. Res., 40, W03512, doi:10.1029/2003WR002436.

Le Borgne, T., O. Bour, F. L. Paillet, and J.-P. Caudal (2006a), Assessment of preferential flow path connectivity and hydraulic properties at singleborehole and cross-borehole scales in a fractured aquifer, J. Hydrol., 2, 347-359.

Le Borgne, T., F. L. Paillet, O. Bour, and J.-P. Caudal (2006b), Cross borehole flowmeter tests for transient heads in heterogeneous aquifers, Ground Water, 44(3), 444-452.

Le Borgne, T., et al. (2007), Comparison of alternative methodologies for identifying and characterizing preferential flow paths in heterogeneous aquifers, J. Hydrol., 345, 134-148.

Lee, J. Y., and K. K. Lee (2000), Use of hydrologic time series for identification of recharge mechanism in a fractures bedrock aquifer system. $J$. Hydrol., 229, 190-201.

Leray, S., J.-R. de Dreuzy, O. Bour, T. Labasque, and L. Aquilina (2012), Contribution of age data to the characterization of complex aquifers, $J$. Hydrol., 464-465, 54-68.

Li, S.-G., and D. McLaughlin (1991), A nonstationary spectral method for solving stochastic groundwater problems: Unconditional analysis, Water Resour. Res., 27(7), 1589-1605.

Li, S.-G., and D. McLaughlin (1995), Using the nonstationary spectral method to analyze flow through heterogeneous trending media, Water Resour. Res., 31(3), 541-551.

Lumley, J., and H. Panofsky (1964), The Structure of Atmospheric Turbulence, Wiley-Interscience, New York.

Long, A. J., and R. G. Derickson (1999), Linear systems analysis in a karst aquifer, J. Hydrol., 219(3-4), 206-217.

Long, J., et al. (1996), Rock Fractures and Fluid Flow: Contemporary Understanding and Applications, Natl. Acad. Press, Washington, D. C.

Manga, M. (1999), On the timescales characterizing groundwater discharge at springs, J. Hydrol., 219, 56-69.

Maréchal, J. C., B. Dewandel, and K. Subrahmanyam (2004), Use of hydraulic tests at different scales to characterize fracture network properties in the weathered-fractured layer of a hard rock aquifer, Water Resour. Res., 40, W11508, doi:10.1029/2004WR003137.

Maréchal, J. C., B. Dewandel, S. Ahmed, L. Galeazzi, and F. K. Zaidi (2006), Combined estimation of specific yield and natural recharge in a semi-arid groundwater basin with irrigated agriculture, J. Hydrol., 329, 281-293.

Martinez-Landa, L., and J. Carrera (2005), An analysis of hydraulic conductivity scale effects in granite (Full-scale Engineered Barrier Experiment (FEBEX), Grimsel, Switzerland), Water Resour. Res., 41, W03006, doi:10.1029/2004WR003458.

Molenat, J., P. Davy, C. Gascuel-Odoux, and P. Durand (1999), Study of three subsurface hydrologic systems based on spectral and cross-spectral analysis of time series, J. Hydrol., 222(1-4), 152-164.

Molz, F. J., O. Guven, J. G. Melville, and C. Cardone (1990), Hydraulic conductivity measurement at different scales and contaminant transport modeling, in Dynamics of Fluids in Hierarchal Porous Media, edited by J. H. Cushman, pp. 35-79, Academic Press Inc., London.

Moreau, F., O. Dauteuil, O. Bour, and P. Gavrilenko (2006), GPS measurements of ground deformation induced by water level variations into a granitic aquifer (French Brittany), Terra Nova, 18(1), 50-54.

National Research Council (1996), Rock Fractures and Fluid Flow, 551 pp., National Academy Press, Washington, D.C.

Neuman, S. P. (2005), Trends, prospects and challenges in quantifying flow and transport through fractured rocks, Hydrogeol. J., 13, 124-147.

Neuman, S. P., and G. de Marsily (1976), Identification of linear systems response by parametric programming, Water Resour. Res., 12(2), 253262.

Neuman, S. P., and V. Di Frederico (2003), Multifaceted nature of hydrogeologic scaling and its interpretation, Rev. Geophys., 41(3), 1014, doi:10.1029/2003RG000130.

Orfanidis, S. J. (1996), Introduction to Signal Processing, 798 pp., Prentice-Hall, Englewood Cliffs, N. J.

Paillet, F. L. (1998), Flow modeling and permeability estimation using borehole flow logs in heterogeneous fractured formations, Water Resour. Res., 34(5), 997-1010.

Pawlowicz, R., B. Beardsley, and S. Lentz (2002), Classical tidal harmonic analysis including error estimates in MATLAB using T_TIDE, Comput. Geosci., 28, 929-937. 


\section{JIMÉNEZ-MARTÍNEZ ET AL.: TEMPORAL AND SPATIAL SCALING IN FRACTURED AQUIFERS}

Praamsma, T. W., K. S. Novakowski, T. K. Kyser, and K. Hall (2009), Using stable isotope and hydraulic head data to investigate groundwater recharge and discharge in a fractured rock aquifer, J. Hydrol., 366, 35-45.

Priestley, M. B. (1981), Spectral Analysis and Time Series, Elsevier, New York.

Ruelleu, S., F. Moreau, O. Bour, D. Gapais, and G. Martelet (2010), Impact of gently dipping discontinuities on basement aquifer recharge: An example from Ploemeur (Brittany, France), J. Appl. Geophys., 70, 161-168.

Rodhe, A., and N. Bockgard (2006), Groundwater recharge in a hard rock aquifer: a conceptual model including surface-loading effects, $J$. Hydrol., 330, 389-401.

Rovey, C. W., and D. S. Cherkauer (1995), Scale dependency of hydraulic conductivity measurements, Ground Water, 33(5), 769-780.

Sanchez-Vila, X., J. Carrera, and J. P. Girardi (1996), Scale effects in transmissivity, J. Hydrol., 183(1-2), 1-22.

Sanchez-Vila, X., P. M. Meier, and J. Carrera (1999), Pumping tests in heterogeneous aquifers : An analytical study of what can be obtained from their interpretation using Jacob's method, Water Resour. Res., 35(4), 943-952.

Savitzky, A., and M. J. E. Golay (1964), Smoothing and differentiation of data by simplified least squares procedures, Anal. Chem., 36 (8), $1627-$ 1639 .

Scanlon, B., R. Healy, and P. Cook (2002), Choosing appropriate techniques for quantifying groundwater recharge, Hydrogeol. J., 10 (1), 18-39.

Shapiro, A. M. (2003), The effect of scale on the magnitude of formation properties governing fluid movement and chemical transport in fractured rock, in Proceedings of Groundwater in Fractured Rock, edited by $\mathrm{J}$ Krásný, Z. Hrkal, and J. Bruthans, pp. 13-14, IHP-VI Series on Groundwater No. 7, Prague.

Skaggs, T., Z. Kabala, and W. Jury (1998), Deconvolution of a nonparametric transfer function for solute transport in soils, J. Hydrol., 207, 170 178

Smith, A. J. (2008), Weakly nonlinear approximation of periodic flow in phreatic aquifers, Ground Water, 46(2), 228-238.

Talley, J., G. S. Baker, M. W. Becker, and N. Beyrle (2005), Four dimensional mapping of tracer channelization in subhorizontal bedrock frac- tures using surface ground penetrating radar, Geophys. Res. Lett., 32, L04401, doi:10.1029/2004GL021974.

Theis, C. V. (1935), The relation between the lowering of the piezometric surface and the rate and duration of discharge of a well using groundwater storage, Eos Trans. AGU, 16, 519-524.

Trinchero, P., R. Beckie, X. Sanchez-Vila, and C. Nichol (2011), Assessing preferential flow through an unsaturated waste rock pile using spectral analysis, Water Resour. Res., 47, W07532, doi:10.1029/ 2010WR010163.

Tsang, C. F., and I. Neretnieks (1998), Flow channeling in heterogeneous fractured rocks, Rev. Geophys., 36, 275-298.

Tsoflias, G. P., and A. Hoch (2006), Investigating multi-polarization GPR wave transmission through thin layers: Implications for vertical fracture characterization, Geophys. Res. Lett., 33, L20401, doi:10.1029/ 2006GL027788.

Touchard, F. (1999), Caractérisation hydrologique d'un aquifère en socle fracture, Ph.D. thesis, in Mémoires de Géosciences Rennes, number 87, 271 pp., Geosci. Rennes, Rennes, France.

Verma, R. D., and W. Brutsaert (1971), Unsteady free surface ground water seepage, J. Hydraul. Div. Amer. Soc. Civil Eng.., 97(HY8), 1213-1229.

Vesselinov, V. V., S. P. Neuman, and W. A. Illman (2001), Threedimensional numerical inversion of pneumatic cross-hole tests in unsaturated fractured tuff: 2. Equivalent parameters, high-resolution stochastic imaging and scale effects, Water Resour. Res., 37, 3019-3042.

Welch, P. D. (1967), The use of fast Fourier transform for the estimation of power spectra: a method based on time averaging over short, modified periodograms, IEEE Trans. Audio Electroacoust., AU-15, 70-73.

Williams, J. H., and F. L. Paillet (2002), Using flowmeter pulse tests to define hydraulic connections in the subsurface: A fractured shale example, J. Hydrol., 265(1-4), 100-117.

Zhang, Y.-K., and K. Schilling (2004), Temporal scaling of hydraulic head and river base flow and its implication for groundwater recharge, Water Resour. Res., 40, W03504, doi:10.1029/2003WR002094.

Zhang, Y.-K., and Z. Li (2005), Temporal scaling of hydraulic head fluctuations: nonstationary spectral analyses and numerical simulations, Water Resour. Res., 41, W07031, doi:10.1029/2004WR003797. 